\title{
ANCILLARY OPERATIONS IN COAL PREPARATION INSTRUMENTATION: ON-LINE LOW COST SULFUR AND ASH ANALYSIS
}

\author{
EIGHTH QUARTERLY REPORT \\ FOR THE PERIOD \\ JULY 1990 THROUGH SEPTEMBER 1990
}

PPEPARED BY:

\author{
THE BABCOCK \& WILCOX COMPANY \\ RESEARCH AND DEVELOPMENT DIVISION \\ P. O. BOX 835 \\ ALLIANCE, OHIO 44601
}

\author{
PREPARED FOR \\ U. S. DEPARTMENT OF ENERGY \\ PITTSBURGH ENERGY TECHNOLOGY CENTER \\ P. O. BOX 10940 \\ PITTSBURGH, PA 15236-0940 \\ DOE: $D E-A C 22-88 P C 88882$ \\ $B \& W$ : CRD 1222
}

\section{DISCLAIMER}

This report was piepared as an account of work sponsored by an agency of the United States Government. Neither the United States Grovernment nor any agency thereof, nur any of their employees, makes any warranty, express or implied, or assumes any legal liability or esponsibility for the accuracy, completeness, or usefulness of any information, apparatus, product, or process disclosed, or represents that its use would not infringe privately owned rights. Reference herein to any specific commercial product, process, or service by trade name, trademark, manufacturer, or otherwise does not necessarily constitute or imply its endorsement, recom. mendation, or favoring by the United States Government or any agency thereof. The views anc opinions of authors expressed herein do not necessarily state or reflect those of the United istates Government or any agency thercof.

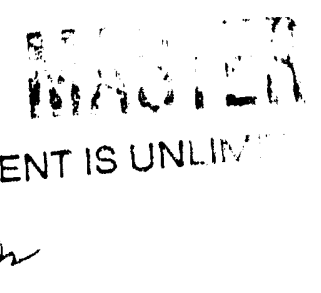




\section{Contents}

1.0 Introduction

2. o Summary of Project status

2.1 Summary of Technical Accomplishments

2.2 Discussion of Testing and Results To Date

2.3 Schedule/Budget

ATTACHMENTS

A. Draft Test Plan for Analysis of Field Collected Coal slurries

B. Equipment Arrangement Sket.ches for Field Tests

C. Table of Test Data and Results

D. PSD Results on Calibration slurries (SQ3')

E. Results of Opacity Calibration and Solids Testing on Field collected slurries 


\subsection{Introduction}

Included in the current quarterly report is a summary of the activities completed during the months of July through september $19 \%$. The DOE Project Forms F1332.2 (Summary Report Form), F1332.9 (Cost Management Report Form), and F1332.3, (Milestone Schedule status Report Form) are not part of this report but have been included in the september monthly report (submitted under separate cover).

\subsection{Summary of Project Status}

\subsection{Summary of Technical Accomplishments}

-The assembly of the sample preparation and delivery (SPAD) system was completed and laboratory pretesting performed.

-The system software was completed and debugged.

-The system was transported to C.Q. Inc. in Homer City Pa.

-The Netzsch grinding mill was transported to C.Q. Inc.

-The entire system was assembled and debugged at C.Q. Inc.

-Field tests were executed according to the Field Test Plan with certain modifications necessitated by actual field conditions and C.Q. test schedule.

- Coal slurry samples collected at C.Q. Inc. were either sent to the Homer city Coal Lab or brought back to B\&W for ICP analysis.

-Homer City Coal Lab analysis of field collected slurry samples was completed and results reported to $B \& W$.

-At the completion of testing at C.Q. Inc., the SPAD-system was dismantled and all equipment, with the exception of the Netzsch grinder, returned to the $B \& W$ laboratory in Alliance, ohio. The Netzsch grinder was returned to Netzsch Inc. 
- Subsequent to the field testing, the opacity meter was reassembled at the $B \& W$ research center and calibrated using "waste" slurry samples (SQ3') collected during the rield tests. The field collected slurry samples, SC4, were then run through the opacity meter and solids computed. The results of these "post-site" of solids tests were compared to the site computed of solids (also by opacity) and the Homer City Coal Lab moisture analysis (performed by conventional drying and weighing). The results are presented in attachment $\mathrm{E}$.

- A test plan for the analysis of the field collected slurries was prepared (see attachment A).

\subsection{Discussion of Testing and Results To Date}

A summary of the tests executed at C.Q. Inc. and the results to date (Homer city Coal Lab assay and $q$ solids by opacity) are presented in table 1 of attachment $c$. Four tests were executed at the C.Q. facility and are each briefly described below.

The first two tests were executed on an Upper Freeport coal (see data sheet in attachment $C$ ) being run for a Batelle project which is evaluating a new dewatering device. Prior to the first test, the system was run for two days with coal slurry from the froth flotation feed. During those "pretests" it was discovered that the lowest set of cutters in the multistage sampler was prone to clogging on unground coal slurry. The lowest stage sampler had been designed with smaller tube diameters to minimize inventory when sampling ground coal slurry for feed to the ICP. The tests on unground slurry would therefore have to be executed using the first and second samplers rather than the second and third sampler, as described in the Field Test plan.

Also during the pretesting, the Netzsch grinder was loaded with grinding media and run with coal slurry from the froth flotation tank. The output of the grinder was pumped to the multistage sampler and diluted with filtered well water (see figure 2 of attachment $B$ ). During this pre-test it was discovered that anti foam agent would be required to minimize foaming in the upper mixing tank. A problem with the solenoid actuated pinch valve was also identified. As the pinch valve was actuated, closing one leg of a Y-connection, the other leg of the $Y$ did not open immediately (it took some seconds for the pinched tubing to recover its shape). The result was that the peristaltic pump caused excess pressure in the tubing and the tubing separated from the fittings. In addition, even the ground coal slurry could occasionally clog the tiny tube fittings connecting the peristaltic pump to the opacity meter. 
Because of the problems with the peristaltic pump tubing/fittings/valves, the tubing was replaced with larger diameter tubing and the solenoid valve was replaced by hand operated valves. A future system would have to be equipped with separate valves for each leg of the $Y$-connection (or better yet, the slurry feed to the ICP should be such that continuous on-line opacity/solids measurement could be made). It was B\&'W's intention to continue with pre-testing when $C . Q$. Inc. was unexpectedly informed by Batelle that they would be halting testing until later in the year. Since the next day's coal had already been loaded into the system, C.Q. offered to run the plant one more day with the Upper Freeport coal for B\&W's purposes. Since this would be the last chance to obtain data on the Upper Freepurt coal, the first two tests were executed, even though the system was not 100 \% debugged.

2.2.1 Test 1: Feed-No Gxinder-Upper Freeport (Figure 1, Attach. B)

Initially, it was intended to execute the test with the grinder in-line. However the Netzsch grinding mill could not be brought to the proper speed and eventually shut. itself down on an overload signal. After wasting approximately two hours trying to solve the grinder problem, it was decided to switch over to a "No-Grinder" test. The arrangement of the equipment for that test is depicted in Figure 1 of attach. B. Note that the elevation of the bottom of the first vezin sampler is only about 12 " above the top of the first mixing tank on the multistage sampler. The hose connecting the sampler to the top tank was supported at multiple locations to overhead beams but still had some minor sags (as depicted in figure 1).

The test was executed using the feed flow to the froth flotation tank (primary sampler set to divert approximately 20 liters/min to the first vezin sampler). The test was run for approximately 2 hours when it was noticed that the first vezin sampler was overflowing. The test was halted and it was discovered that the hose connecting the vezin sampler to the top tank had become clogged with coal particles.

During the two hour test however, the problem with the Netzsch grinder had been traced to a defective RPM meter. The RPM meter indicated a lower RPM than that at which the mill was actually operating. The meter was drifting lower as time went on. As the throttle on the mill was increased to compensate for the apparent low speed, the grinder drew too much power and shut down. On advice from Netzsch, the grinder was set to run at a power consumption of between 6 and 7 amps. At this setting, the grinder performed well as evidenced by the PSDs presented in attachment $D$. 
With the Netzsch grinder problem overcome, the 5 \% cut from the first vezin sampler was directed to the Netzsch grinder feed pump, A drip solution of anti-foam agent and dispersant was started at the same time. The reference sample was started approximately 10 minutes prior to the $t$ irst sample extraction from the multistage sampler.

As a result of problems encountered during the pretesting with the small peristaltic pump tubing and fittings, the output of the last stage of sampling was equipped with larger diameter tubing. This tubing worked extremely well in that it did not clog, however the velocity of slurry through the tubing was so slow that it made opacity readings impractical (by the time slurry reached the opacity meter, the measurement time was over and the slurry was diverted back to the sample container SC4). The tubing connection between the sampler output and the sample container SC4 was made as short as practical by placing the peristaltic pump on the floor of the multistage sampler.

The pressure sensor and software which controlled the fluid level in the vessel collecting the slurry worked very effectively to minimize and stabilize the inventory of slurry in the path between the sampler and the sample container $\mathrm{SC} 4$.

During the course of this test it was decided to draw off a sample (SQ3') of the waste slurry exiting the second stage of the multistage sampler for purposes of having a relatively large slurry specimen on which to calibrate the opacity meter and the ICP during the post-site laboratory testing at the $B \& W$ research center. This was an unplanned sample and no provision had been made to assure that a representative sample could be taken at the waste drain. This sample would be necessary since all samples which were sent to the Homer city Coal Lab would be totally consumed and the samples taken for ICP testing are quite small (approx. $50 \mathrm{ml}$ each). The configuration of the waste exit piping is shown in figure 5 of attach. B. Although the configuration would prevent a representative sample from being taken, it was felt that an unrepresentative sample of the field slurry would be better for calibration purposes than a laboratory prepared sample.

The test was concluded when C.Q. had exhausted the coal that they had loaded on the previous work day. 
The next opportunity to test coal slurry at the C.Q. facility was presented on a project aimed at determining the parameters associated with cleaning of an Oklahoma bituminous coal. Prior to this test, the tubing connecting the output of the sampler, the peristaltic pump, and the opacity meter was redesigned to provide larger tubing in the regions where clogs had been troublesome and use smaller diameter tubing in the longer lengths (e.g. around the peristaltic pump head). With the exception of a sliver of plastic getting caught in a fitting (4 of 12 opacity measurements were missed as a result) the system performed exceptionally well and trouble free. Once again, the Yconnection was switched by hand operated pinch valves to avoid having both legs closed simultaneously.

since $C . Q$. Inc. required their own samples for the tests, they attached a third vezin sampler to the two vezin samplers that $B \& W$ had installed. This required that the tripod on which the vezin samplers were mounted be raised approximately 8". This additional height was also desirable for the test which would be run on unground coal slurry (to provide a greater slope for slurry to travel between the outlet of the first vezin sampler and the top mixing tank of the multistage sampler. The C.Q. supplied vezin sampler had a slight overflow problem throughout the test. It was later discovered (during test \#4) that the sampler inlet had been assembled 180 degrees out of phase with the sample outlet, resulting in poor sampling as the inlet flow increased. In general, the vezin samplers supplied by Denver Equipment were not very precisely manufactured and cannot be considered accurate.

As the C.Q. test began, the flow to the first vezin sampler was much below the expected 20 liter/minute. B\&W waited until the flow could be increased. After much discussion, it was determined that the oklahoma coal had very little fines (the coal was not ground in the ball grinder and thus the only fines were the natural fines). At that point in time it was decided to use the throughput of the third vezin sampler as the input to the grinder (since this approximated the 1 liter/min flow on which the equiprnent was planned) and divert the 5 o cut from the first vezin sampler to the reference sample. The arrangement of equipment for this test is depicted in figure 3 of attach. B.

As with test \#2, a steady drip of antifoam and dispersant was added to the inlet of the grinder feed pump. Also, as in test \#2, an unrepresentative slurry sample from the waste drain of the second sampler stage was collected for calibration purposes (SQ3'). 
As a result of the low volume problem with the concentrate from the froth flotation tank and the inability to arrange the vezin samplers in such a way that the output of the third sampler was at an elevation above the top mixing tank of the multistage sampler, it was decided to execute the last test using froth feed.

To avoid the hose clogging problem that was encnuntered during test \# 1 , the entire vezin sampler tripod was raised approximately $8 "$ and a piece of angle iron was placed between the output of the first vezin sampler and the top of the top mixing tank. The 5 o cutter hose was placed inside the angle iron and thus guided at a constant slope without any sags.

The arrangement of equipment for this test is depicted in figure 4 of attach. B. An additional unplanned sample of slurry was obtained by extracting slurry from the top mixing tank through a peristaltic pump tube suspended at approximately mid depth in the tank. This sample, labeled ST1-1, was sent to the Homer City Coal Lab for analysis.

\section{2 .3 opacity/Solids Testing on Field Collected slurries}

The opacity meter was used on-line in the field for tests 2 \& 3. As mentioned above, however, the results were usable only for test \#3 ( 8 of 12 measurements). It was therefore desirable to analyze the field collected slurries, SC4, for $\%$ solids by opacity at the $B \& W$ research facility subsequent to the field tests.

As a first step, the opacity meter was recalibrated using the "waste" slurries, SQ3', collected during the field tests $2 \& 3$. Although these slurries were not considered representative (as evidenced by the $q \mathrm{~S}$ and $q$ Ash measurements), they were considered preferable to laboratory prepared slurries. The PSD of the two slurries are depicted in figures $2 \& 2$ of attachment $D$. Note that the Upper Freeport coal was ground to a mean particle size of just over 5 microns while the Oklahoma coal (much more difficult to grind) was ground to a mean particle size of appros 3 microns. 
The calibration curves for the two "waste" slurries are shown in figures 1 \& 2 of attachment $E$. The two calibration curves are combined into one curve in figure 3 . Using these calibration curves, the opacity of each field collected slurry, SC4, were run through the opacity meter and the $\%$ solids computed. Figures $4 \& 5$ of attachment $E$ present the comparison of Homer City Coal Lab solids results (on samples SC4'), the opacity meter computed values of solids (on samples SC4) and, in the case of test \#3, the on-line field measurement of solids by way of opacity meter. Note that both the Homer City Lab and the B\&W lab opacity measurements are on samples collected over a 15 minute period, whereas the field opacity measurements are averaged over a one minute sample.

\subsection{Budget/Schedule}

Barring any further complications with the B\&W ICP-AES (it was out of commission for a good part of the month of October), The project should be completed by December $31,1990$. The current budget is sufficient to complete laboratory ICP testing of field collected samples and prepare a project final report. 


\section{ATTACHIENT A}

Draft Test Plan for Analysis of Field Collected Coal slurries 


\title{
ANCILIARY OPERATION'S IN COAL PREPARATION \\ ON-LINE LOW-COST SULFUR AND ASH ANALYSIS
}

\author{
TEST PLAN \\ FOR \\ ANALYSIS OF FIELD COLLECTED CUAL SLURRIES \\ BY ICP-AES
}

\author{
Prepared by: \\ M. I. Malito \\ The Babcock \& Wilcox Company \\ Research and Development Division \\ 1562 Beeson Street \\ Alliance, Ohio 44601 \\ Prepared for: \\ U. S. Department of Energy \\ Pittsburgh Energy Technology Center \\ P. O. Box 10940 \\ Pittshurgh, PA 15236-0940 \\ DOE : DE-AC22-88PC88882 \\ $B \& W$ CRD 1222
}

DRAFT OCT 2,1990 
The purpose of this document is to define the testing to be performed on field collected coal silurry samples by ICP-AES (Inductively Coupled Plasmi-Atomic Emission Spectroscopy). A total of 20 samples ( 8 from an Upper Freeport coal and 12 from an Oklahoma coal) are to je analyzed in triplicate for the elements S, Si, Al, Fe, Ca, AND Mr.

For each of the two coal slurry types (Upper Freeport and Oklahoma), a container of slurry labeled "calibration" has been prepared. These calibration slurries may be used to get the system "tuned" (note that the volume of the field collected slurries is relatively small and cannot be used to "tune" the system).

\section{Equipment}

a $\Gamma \& W$ ICP-AES. Model Applied Research Laboratories $35000:$ ICP consisting $O=$ RF-generator, "torch box", Argon supply, Argon pursed spectrometer, DEC PDPI:L/03L microprocessor, and DECwriter printer.

b Nebulizer/Spray Chamber.

ARi MDSN (see figure )

c slurry feed pump.

Gilson Peristaltic Pump

Model Minipuls 3

$S / N 618 A 9045$

d Mixer.

Cole Parmer Type CT21-18 motor

Cole Parmer Model 4651 controller/mixer

e Tygon Tubing.

Gilson $0.8 \mathrm{cc} / \mathrm{m}$ (red tabs)

f Impellers.

3 blade 1.25" dia. (for stiring $500 \mathrm{ml}$ container)

4 blade $1.75^{\prime \prime}$ dia. (for stirring $1000 \mathrm{ml}$ container)

g Spring loaded laboratory pinch valves.

h stopwatch

i Graduated Cylinder $(0-10 \mathrm{cc})$ 


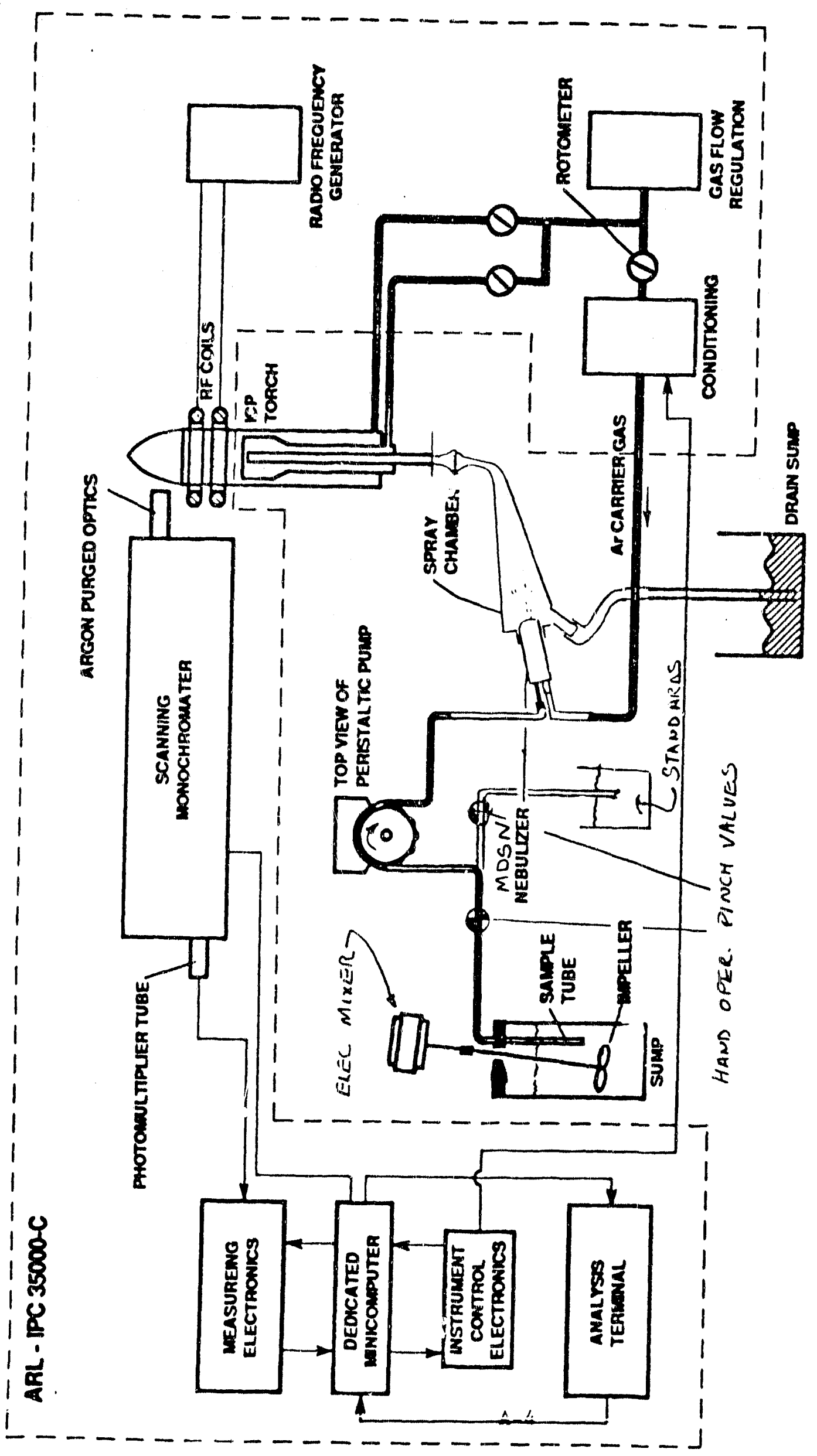



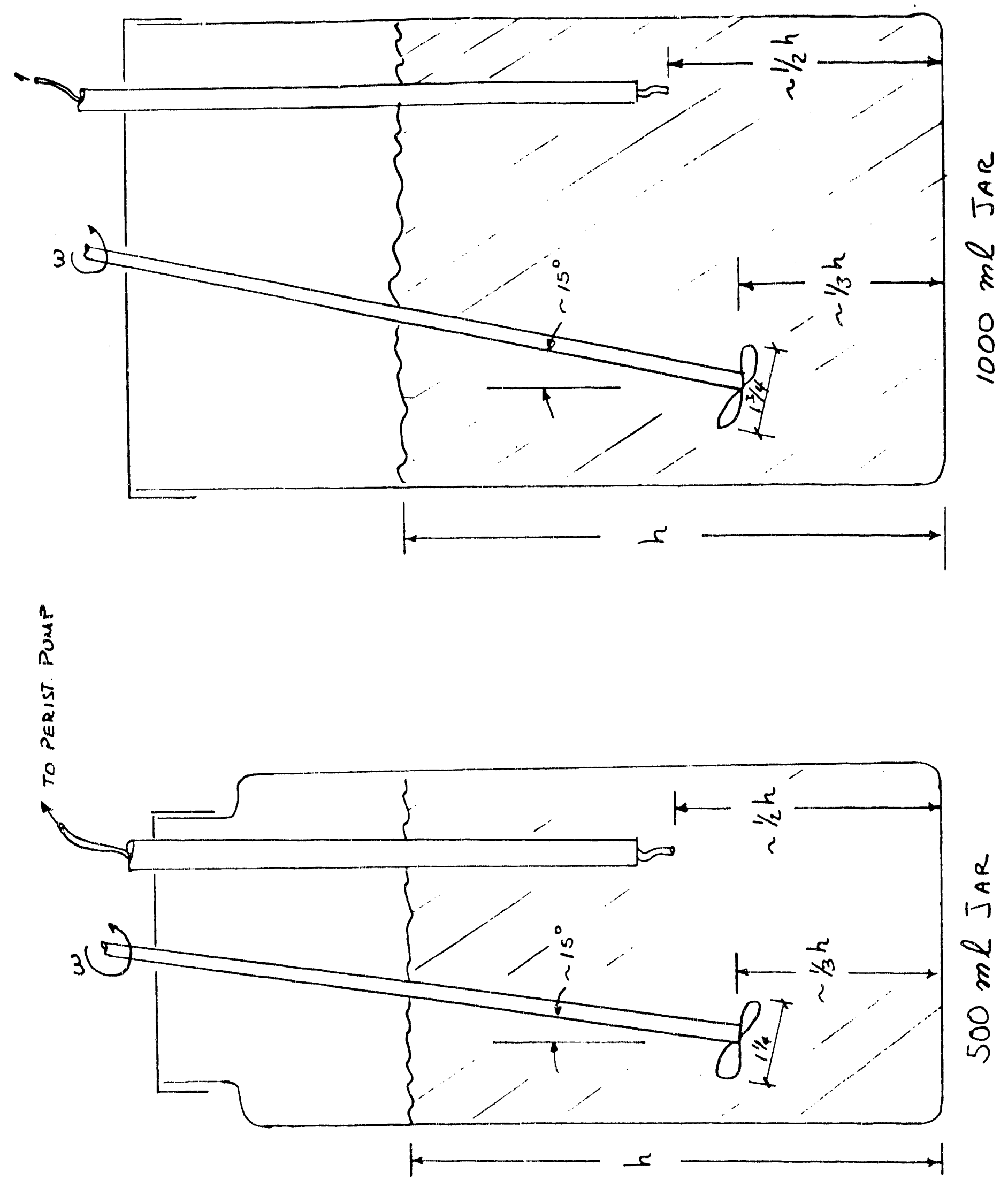
3. Test Procedure

\subsection{Prepare standards}

Primary standards shall be prepared for the purpose of calibrating the ICP. The primary standards should contain each element to be investigaled in concentrations exceeding the maximum concentration expected in the coal slurries. Secondary standards shall also be prepared for the purpose of checking the calibration accuracy periodically during testing. The secondary standards shall contain lower concentrations (e.g. approximating the average of the concentration expected in the coal slurries) of each element than the primary standards. Since two different coal slurry types will be tested (an Upper Freeport and an Oklahoma bituminous), it is desirable to prepare two sets of standards:

$$
\text { Element }\left|\begin{array}{c|c|c|}
\text { U.F.-Standard (PPM) } & \text { Okla-standard (PPM) } \\
\text { Primary } & \text { Secondary } & \text { Primary | Secondary }
\end{array}\right|
$$

\begin{tabular}{|c|c|c|c|c|}
\hline$S$ & 50 & 20 & 100 & 50 \\
\hline$\overline{S i}$ & 50 & 20 & 200 & 100 \\
\hline$\overline{A l}$ & 50 & 20 & 100 & 50 \\
\hline $\mathrm{Fe}$ & 50 & 20 & 100 & 50 \\
\hline $\mathrm{Ca}$ & 10 & 5 & 50 & 20 \\
\hline $\mathrm{Mg}$ & 5 & 2 & 10 & 5 \\
\hline
\end{tabular}

\section{2 set-Up Equipment}

Set up the equipment as depicted in figure . The following parameters are suggested based upon prior testing:

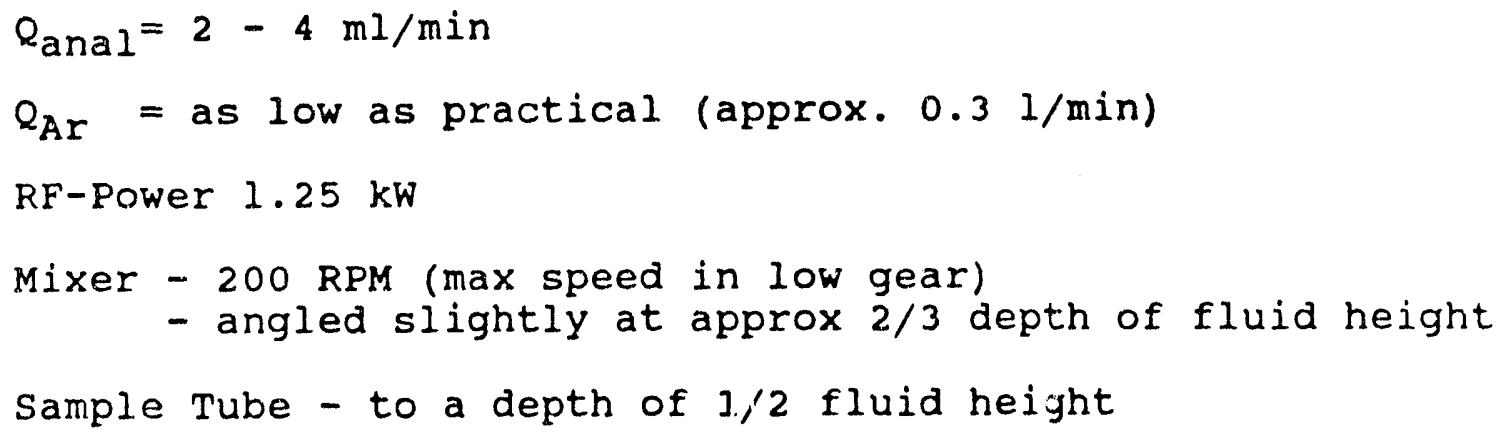


Using a stop watch, a graduated cylinder and a beaker of water, set the peristaltic pump to pump at approx. $3 \mathrm{ml} / \mathrm{min}$.

since the quantity of field collected samples is limited, precaution must be taken to "tune" the system prior to consuming the samples. Two liter containers of "calibration" slurry has been provided for that purpose. The calibration slurries, FGU (Upper Freeport) and CGO (Oklahoma), contain 44 PPM S and 53 PPM S respectively. The ICP shall be calibrated using primary standards and the calibration samples analyzed. The ICP parameters defined in section 3.2 may be adjusted to provide better accuracy and repeatability.

With the parameters selected, the calibration slurries shall be analyzed in triplicate for $s$.

At the conclusion of the shakedown testing the peristaltic pump rate shall be checked and recorded. Small changes in the rate at which the pump operates is expected due to wear of the tygon tubing. Changes of as much as $10 \%$ can be tolerated. If the rate changes by more than $10 \%$, the tygon tubing on the pump head shall be replaced.

3.4 Analysis of FGU Sample Slurries

\subsubsection{ICP Calibration}

Using a stop watch, a graduated cylinder and a beaker of water, set the peristaltic pump to pump at approx. 3 $\mathrm{ml} / \mathrm{min}$.

The ICP shall be calibrated using the appropriate primary $s^{\prime}$ andards. The results of the calibration shall be recorded on data sheet $A$. Be sure to not the value of $Q_{A r}$ since this is a critical parameter.

3.4.2 Analysis of Samples

Each of the FGU samples shall be analyzed for the six elements (S, Si, AI, Fe, Ca, Mg) in triplicate. After the third trial, the secondary stantard shall be analyzed. The results of the slurry analysis and the secondary standards shall be recorded on data sheet $B$ (use a separate data sheet for each slurry sample.

Record the value of $Q_{A F}$ and Refl. Power regularly. If the value of $Q_{A}$ or Refl. Fower change, it may be necessary to clean the nebulizer and spray chamber and recalibrate the system.

At the conclusion of the sample analysis, the peristaltic pump rate shall be checked and recorded. 
3.5 Analysis of CGo Sample Slurries

The procedure described above for the 8 FGU samples shall be repeated for the 12 CGO slurries.

3.6 Analysis of Well WAter

The sample slurries that were collected at the field site were diluted with well water. A sample of that well water has been supplied for analysis. This sample should be analyzed for the six relevant elements either using the set-up prepared for slurry analysis or by the normal ICP procedures (i.e. without peristaltic pump and MDSN nebulizer). 
Table 1 lists the 8 FCU slurry samples and the 12 CGO slurry samples to be analyzed. The estimated concencration of the elements in each of the slurries is also presented. Although the estimated concentrations are approximate for all elements, more faith can be placed in the values for sulfur than the other elements.

The two calibration slurries are also shown in table 2 as is a sample of well water used at the site while collecting slurry samples (slurry samples were diluted with the well water). 


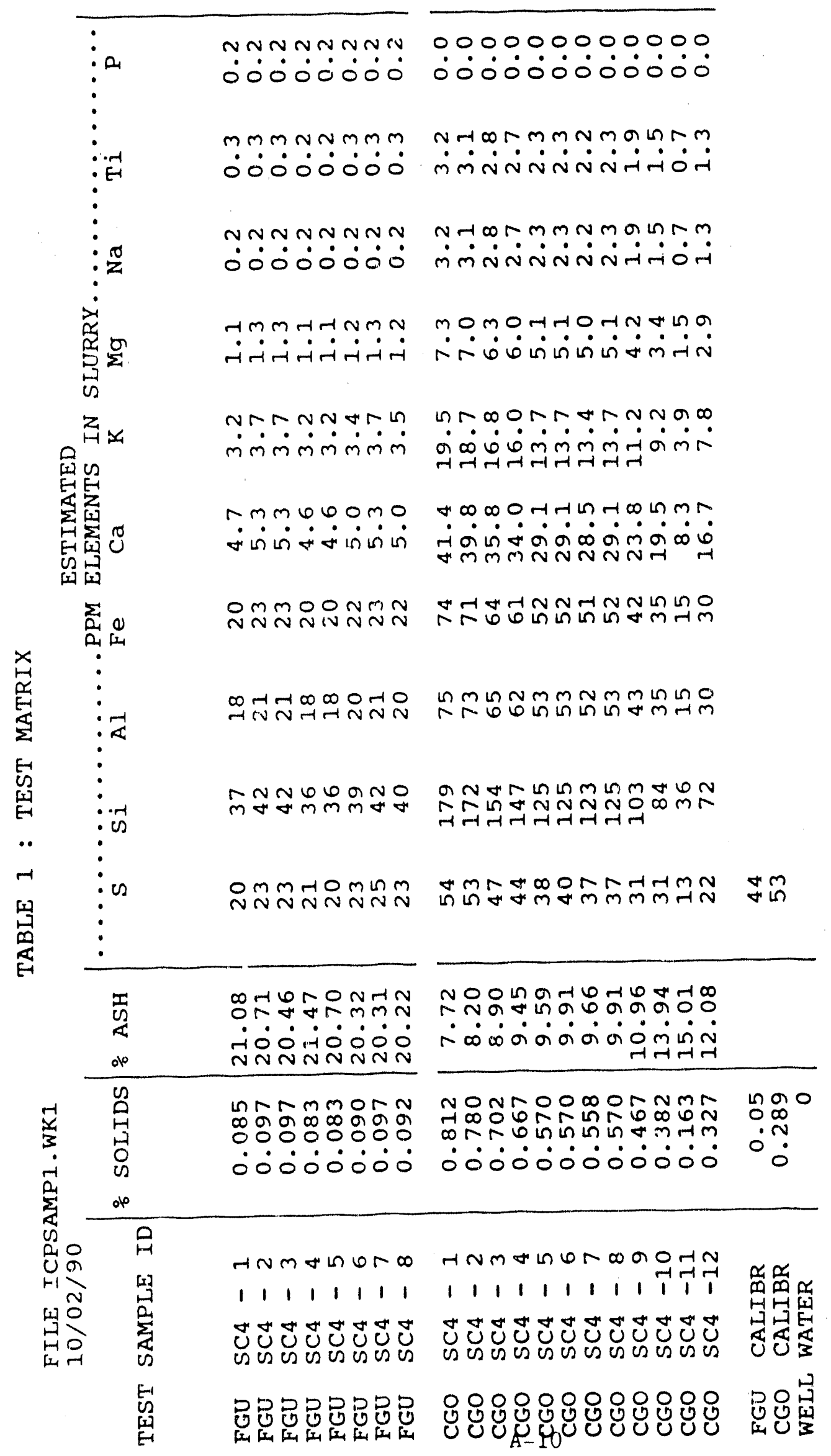




\section{-5.0 Data Sheets}

The two data sheets which follow were prepared for the convenience of the ICP operator. 
DOE SULFUR \& ASH DATA SHEET A

DATE :

PAGE \#:

TIME :

Ar-FLOW RATE (1/min):

ICP POWER LEVEL:

PRIMARY STANDARDS:

|


DOE SULFUR \& ASH DATA SHEET B

DATE :

PAGE \#:

SAMPLE \#:

SOLIDS :

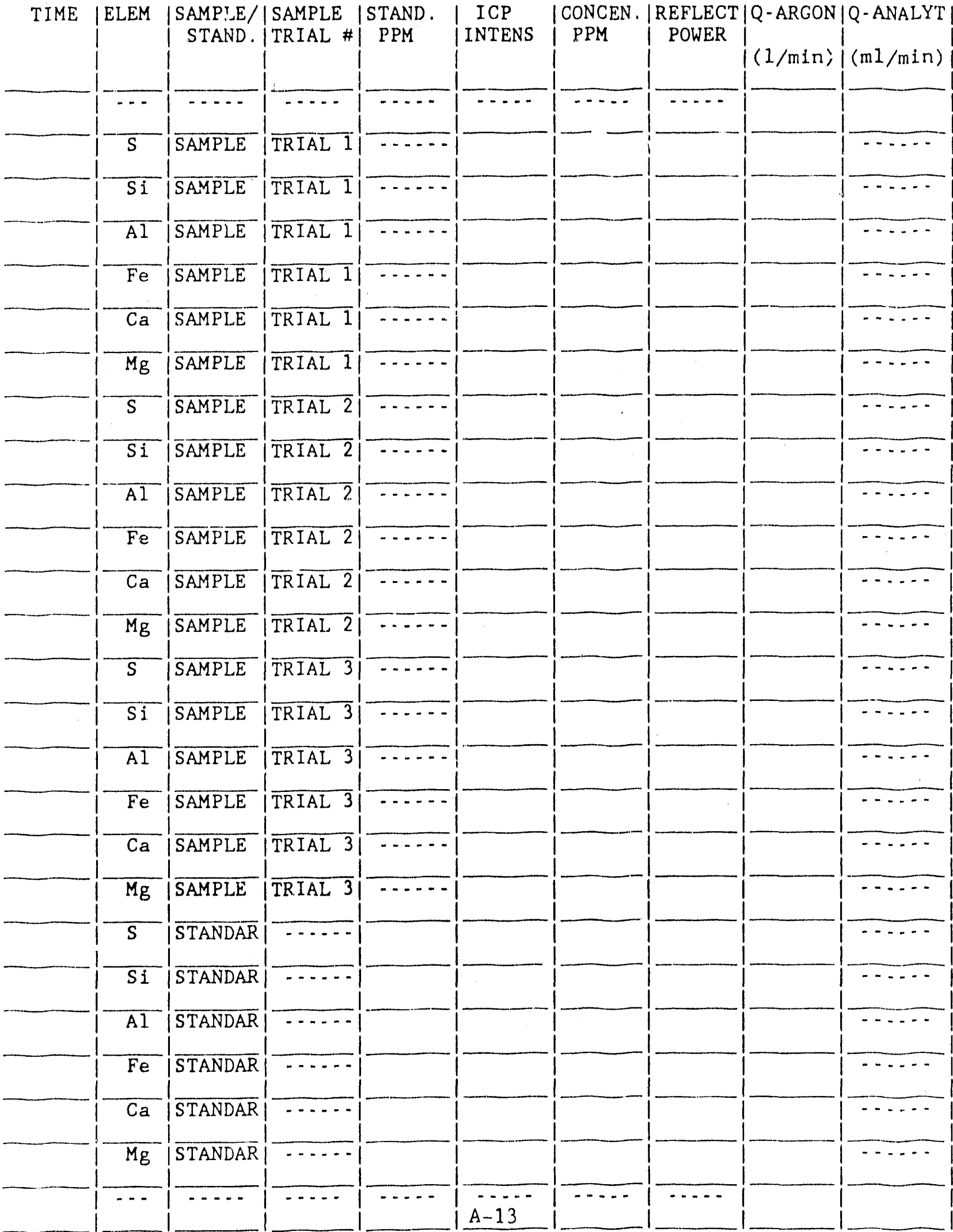


ATTACHMENT B

Equipment Arrangement Sketches for Field Tests

B-1 


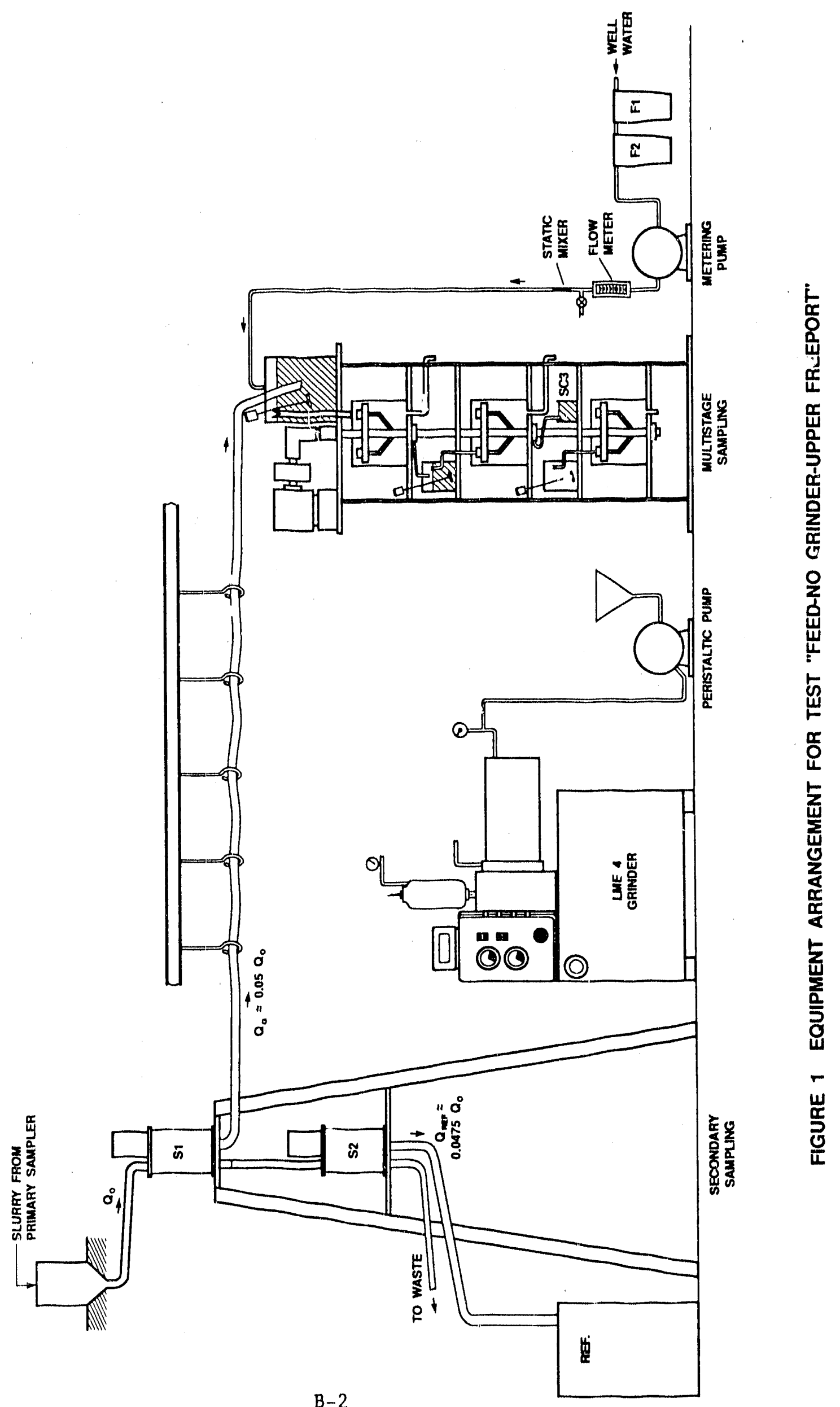




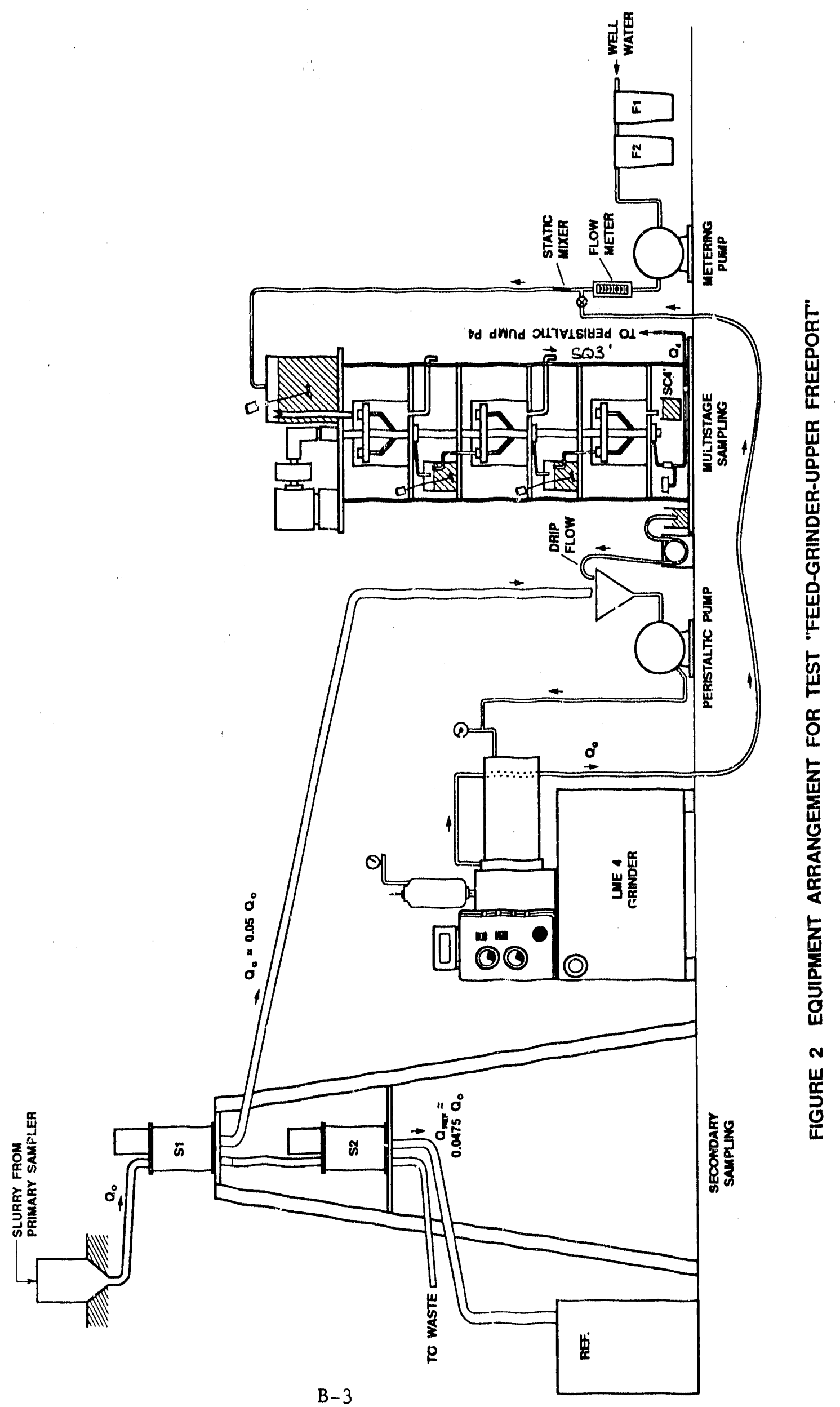




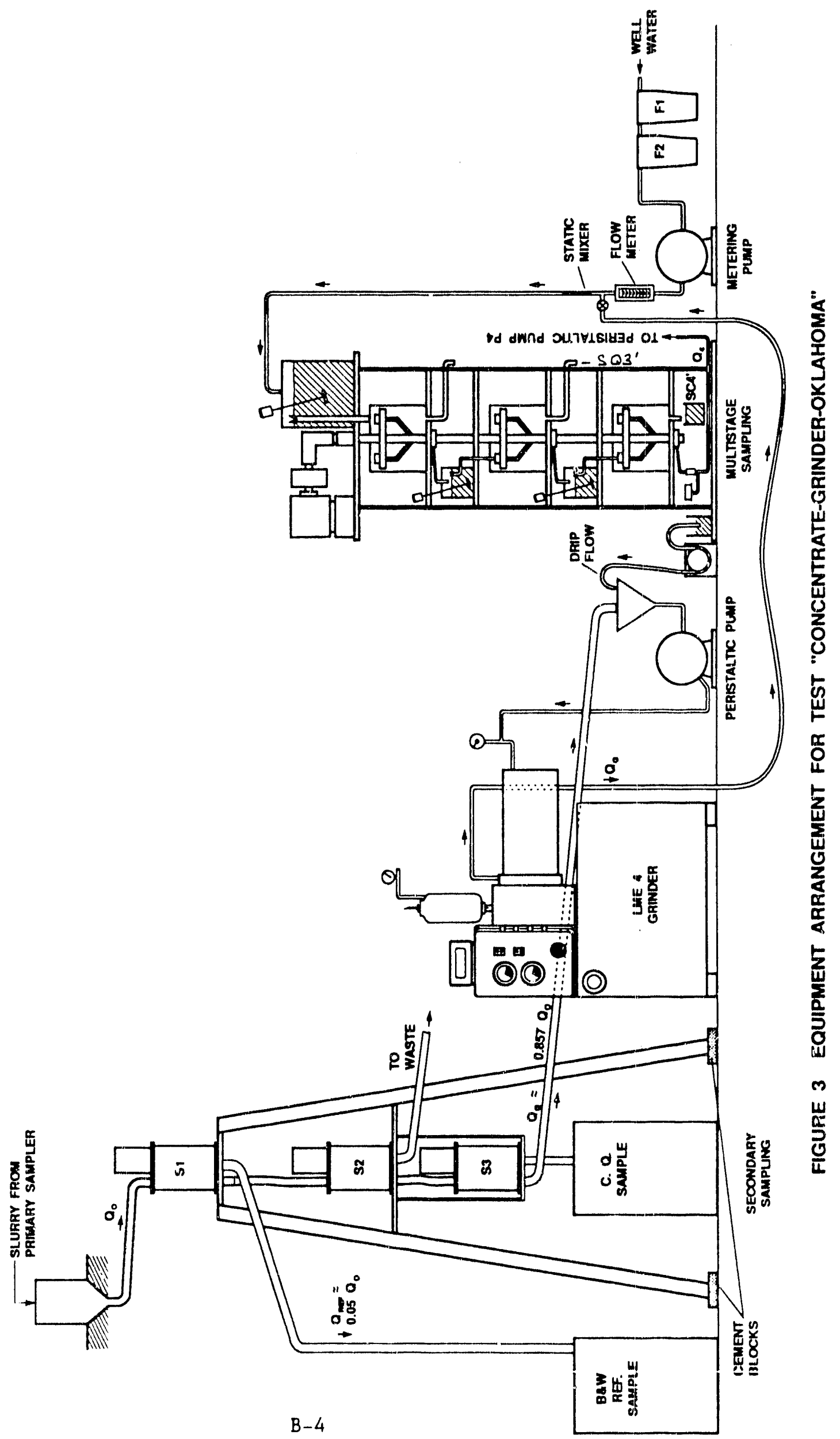




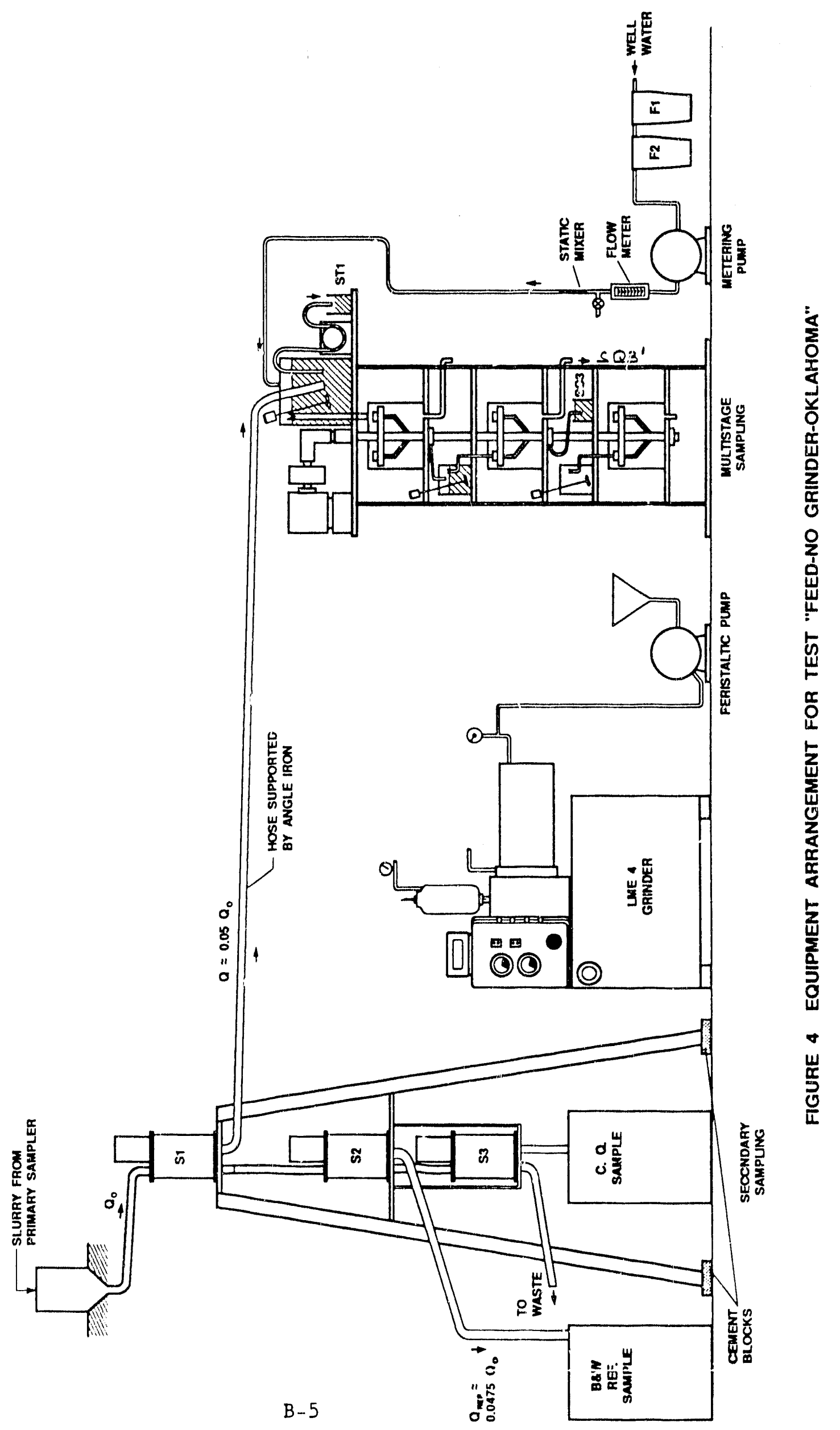




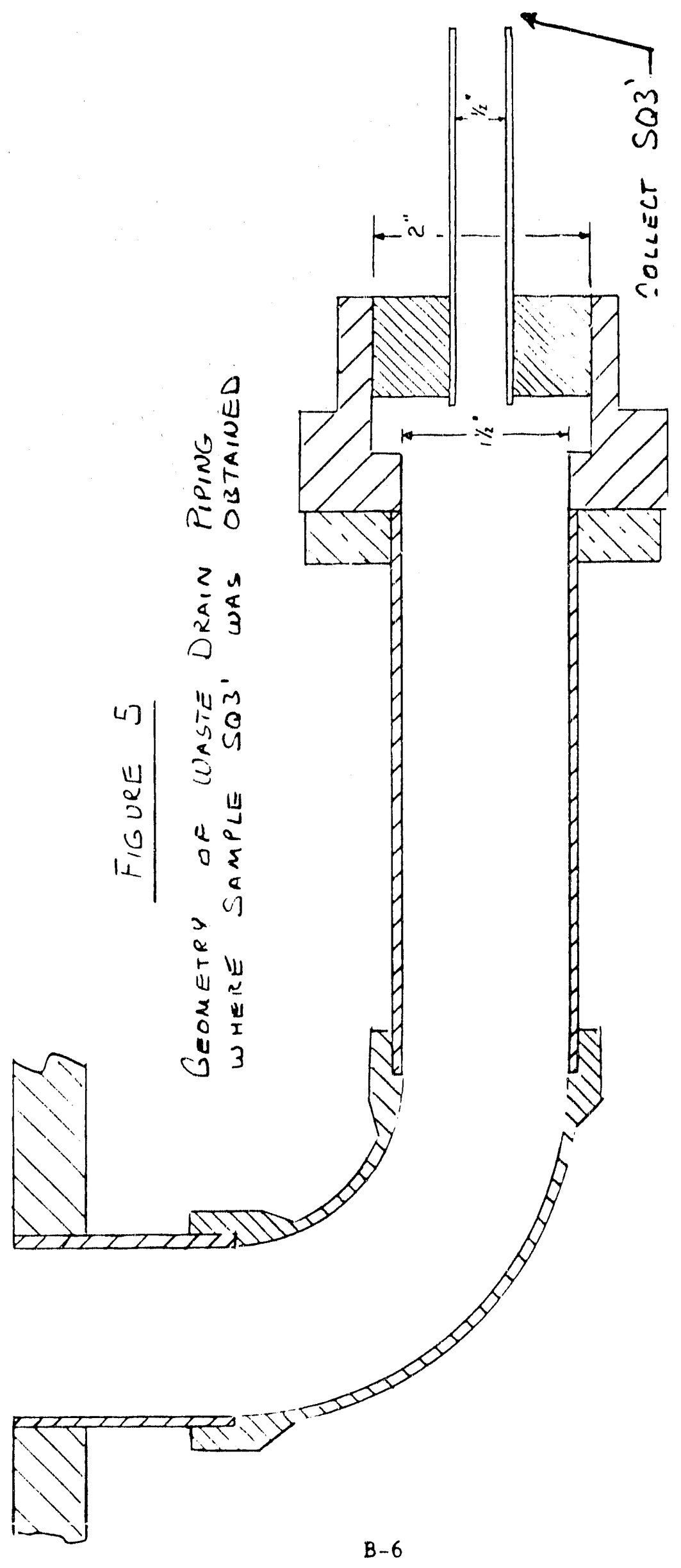


ATTACHMENT $C$

Table of Test Data and Results 


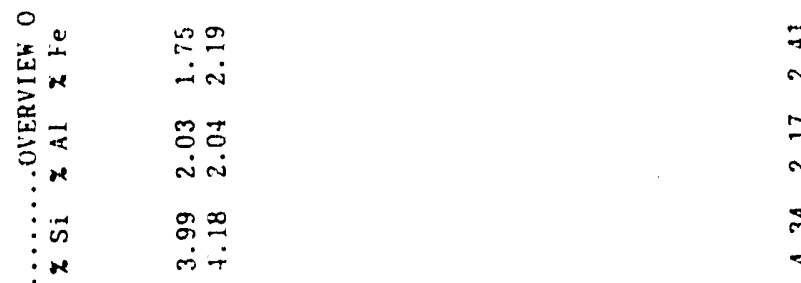

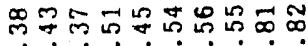

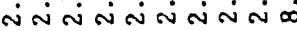

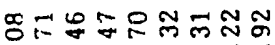
สंड்

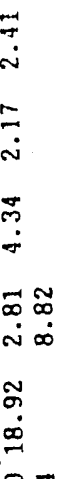

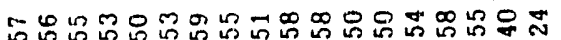

000000000000000000

离

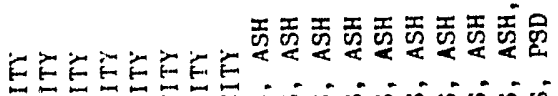

vi

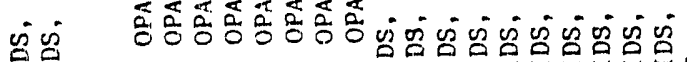

它总

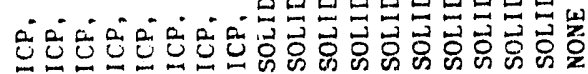

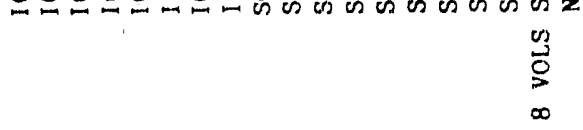

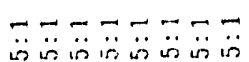

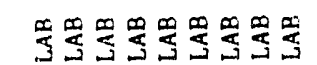

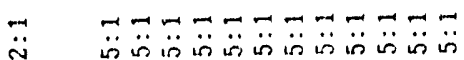

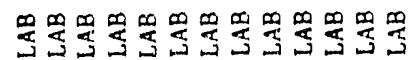

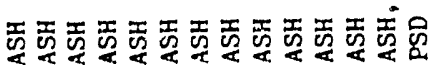

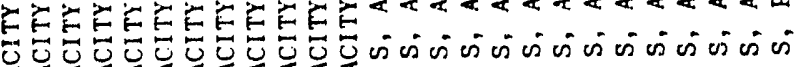

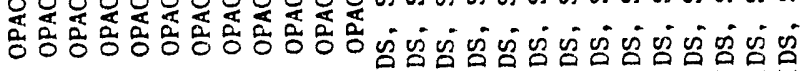

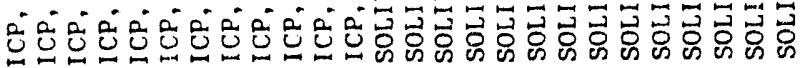

离

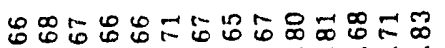
லீல்

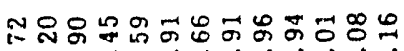

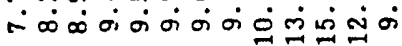

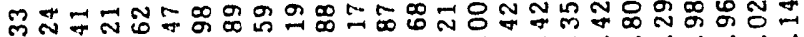
तं $\dot{\mathrm{n}}$

os on 0

离

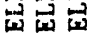

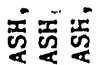

is

ตำ

总勌总品

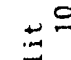

$\pm 0$

$\dddot{m} \div$

罗罢罢

ن

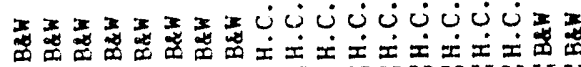

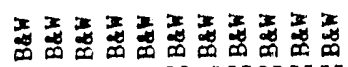
要这

اندنان

*** * * * *

\begin{tabular}{l|l}
0 \\
0 \\
0
\end{tabular}

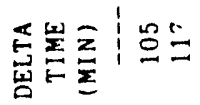

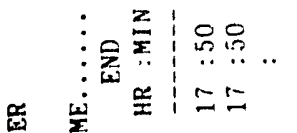

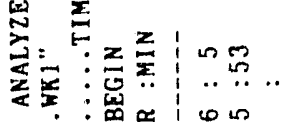

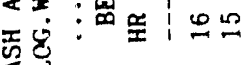

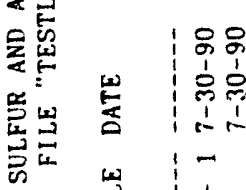

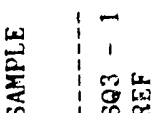

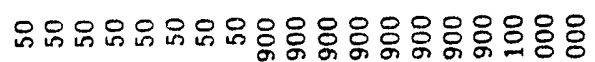

至-

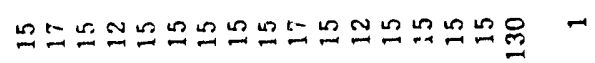

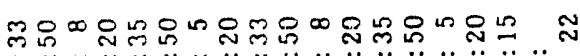

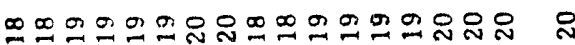

뜨유.

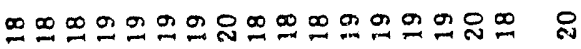

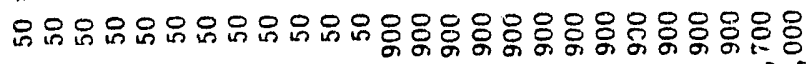

8888

क宫的公

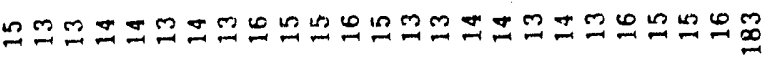

总总总

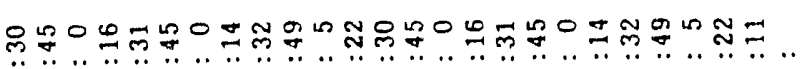

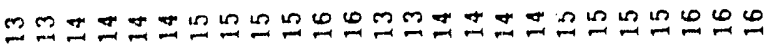

$\ln \operatorname{los}^{\circ}$

.....

ำ

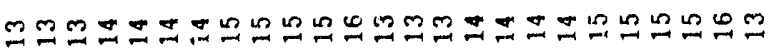

ano

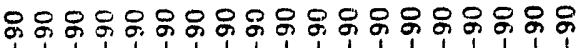

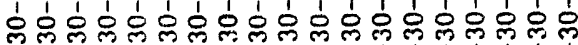

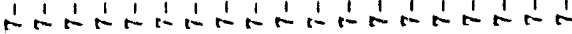

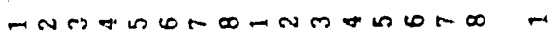

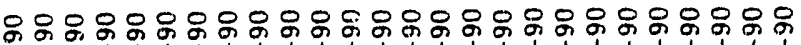

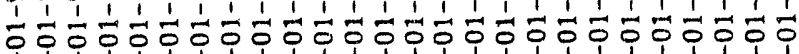

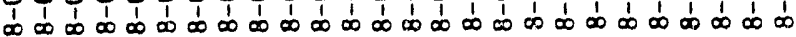
TNm

웅ㅇㅇㅇㅇㅇㅇ

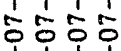

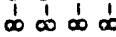
-

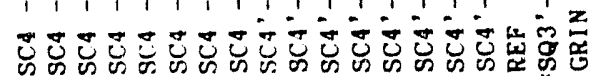

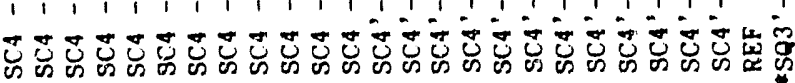

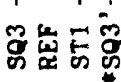

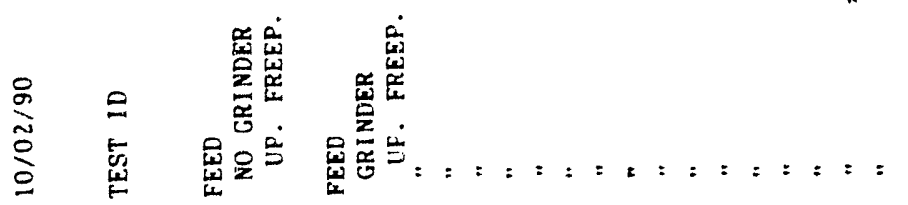

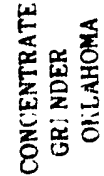

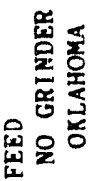




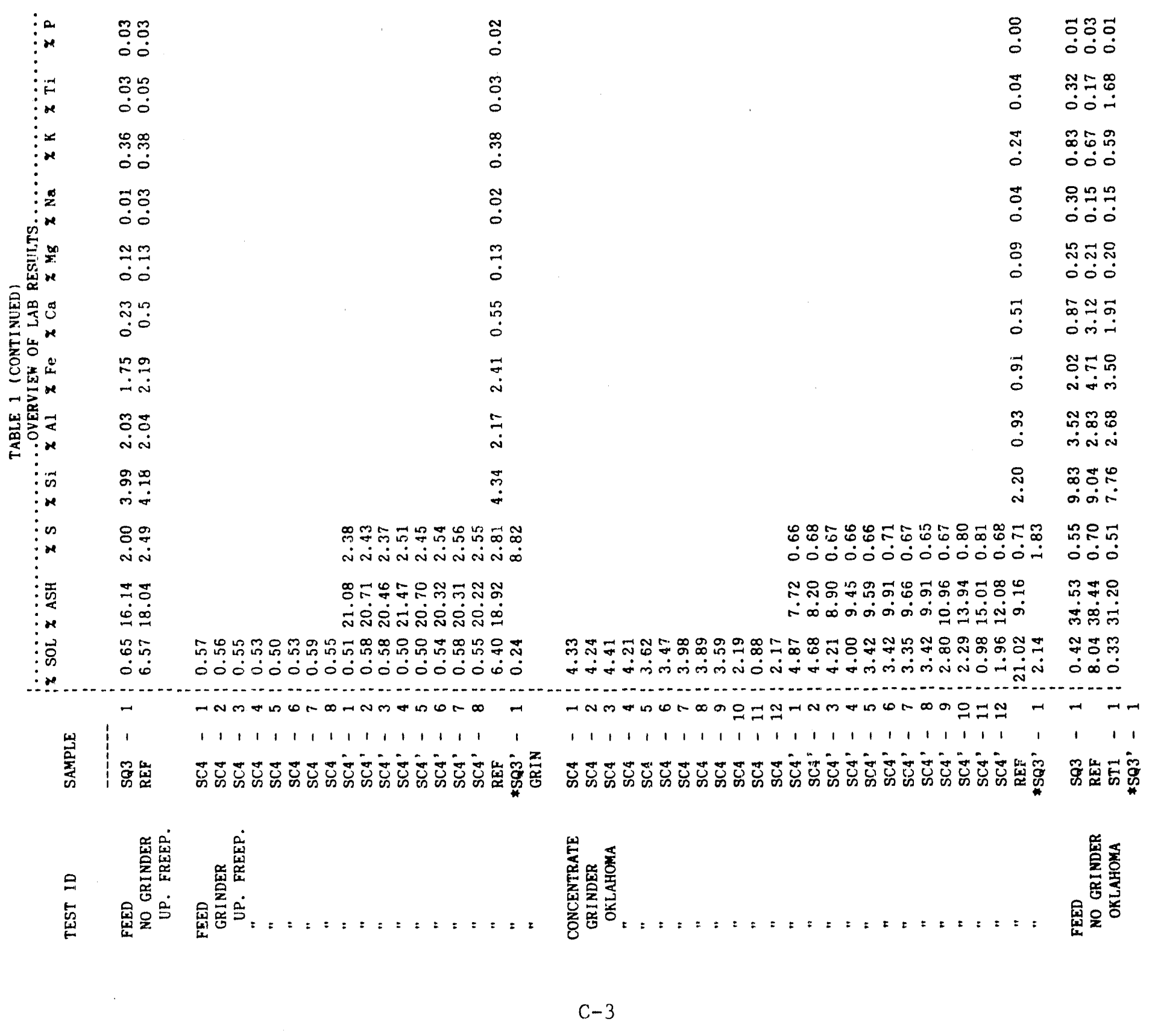




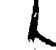

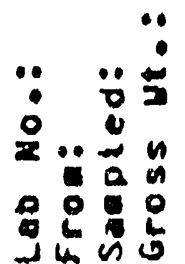

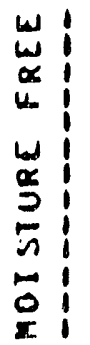

\$ㅇำ

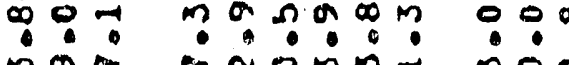
man $\therefore$ in min

๙

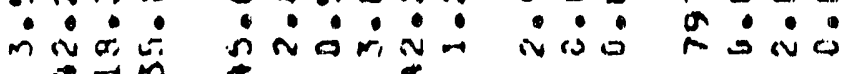

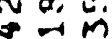

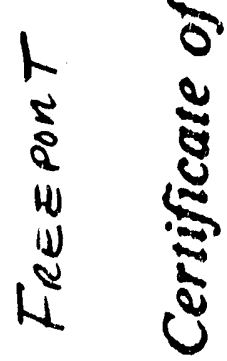
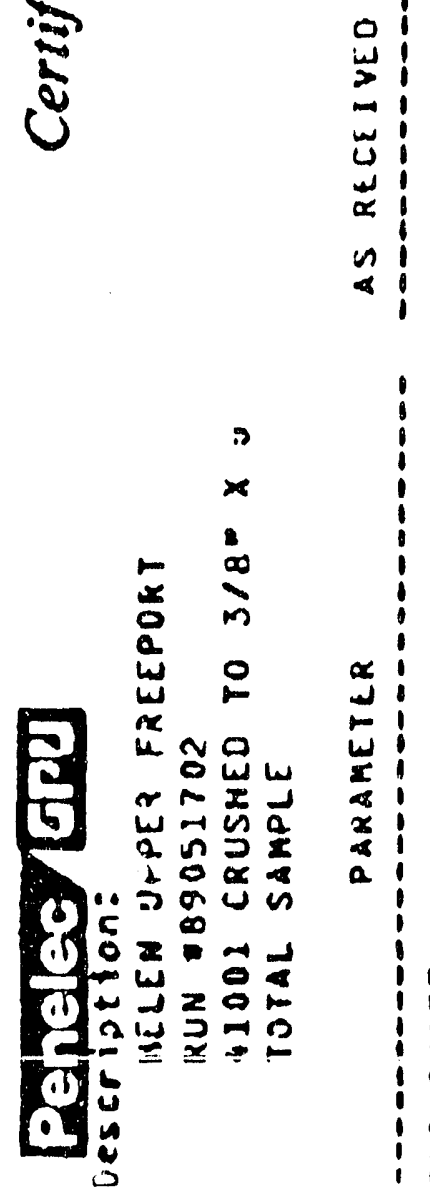

a
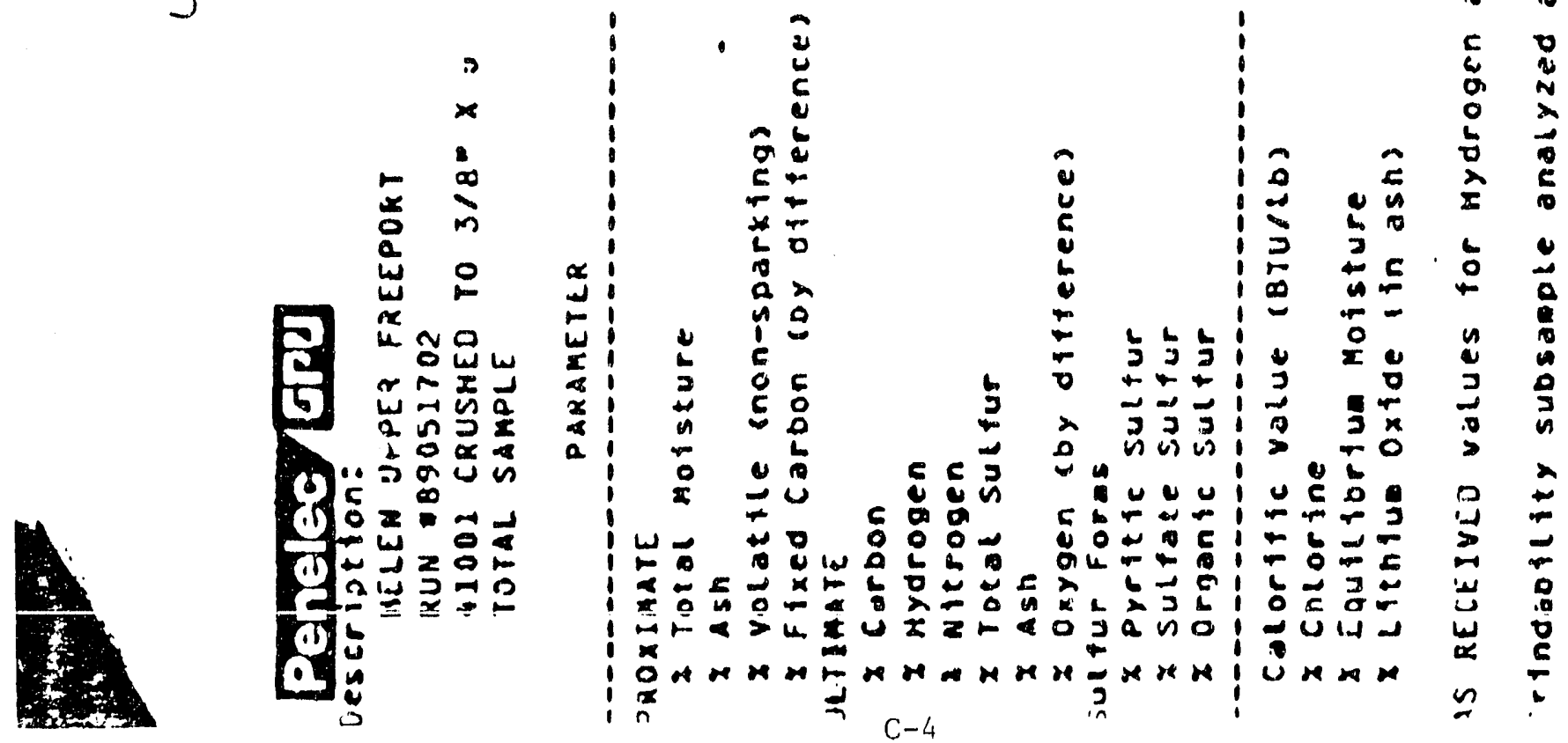
a jair et.

Orlamoma duta sheJey

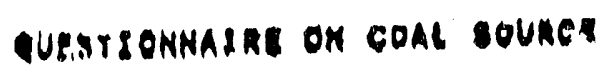

mist hognidey

stare, OKLAHOMA

COUNTY CRAIG, NOWATA ROQERS

IIA.

MHNE, CROWEBURQ

Munerh

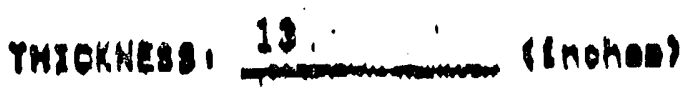

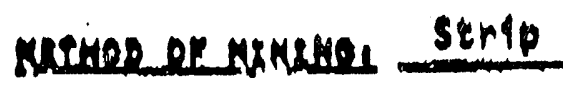

Difi deorosel

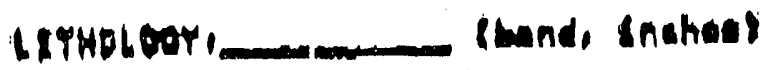

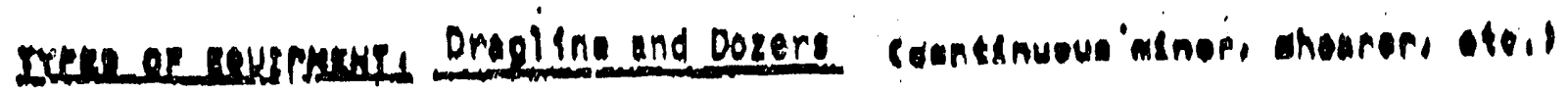

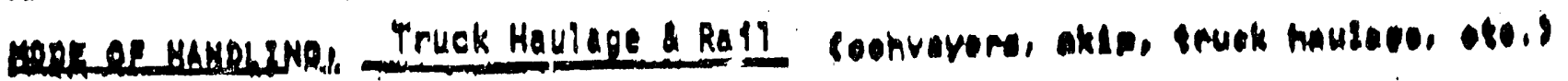

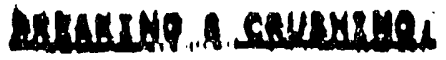

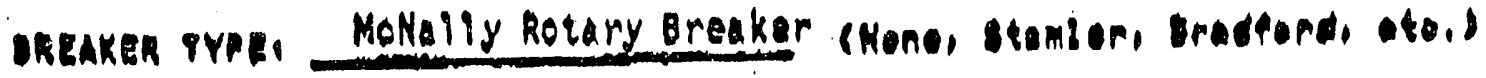

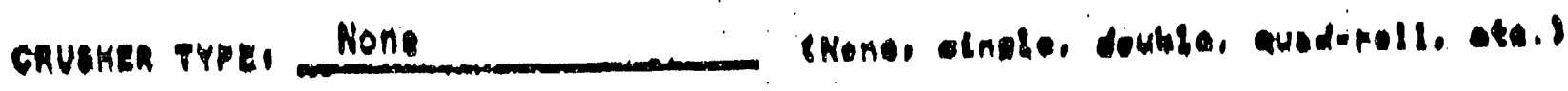

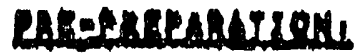

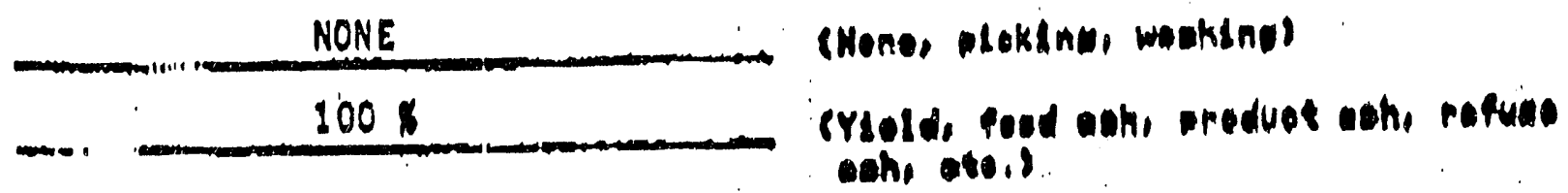

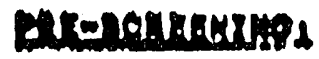

DeneEN rrpes Orfagly

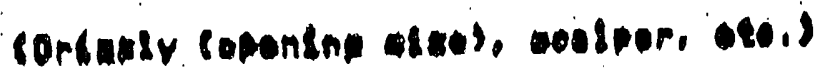

\section{2}

A. MINED,

(28) $\times 0$. sin $x 0$. an $x)$, oto 8

Arren Antaken Q $^{\prime \prime} \times$

16" $\times 0$, 2n $^{\circ} \times 1,0(0,1)$

Aptek CRUBHER!

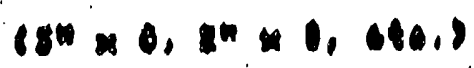

APrER PaE-LCRECHXHO,

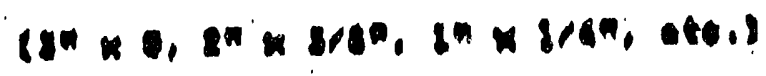

APTER PRE-PREPARATTON,

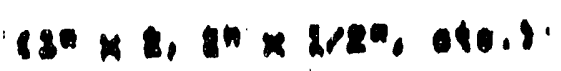




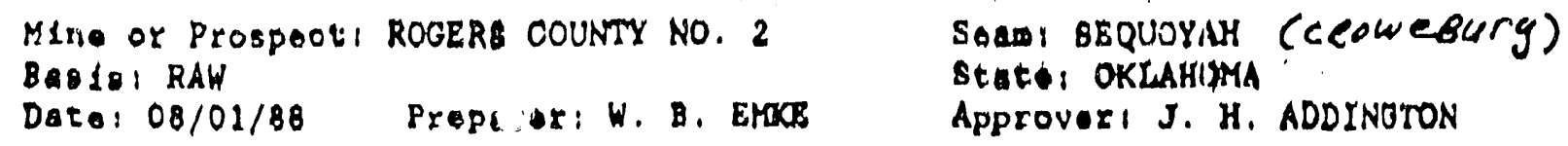

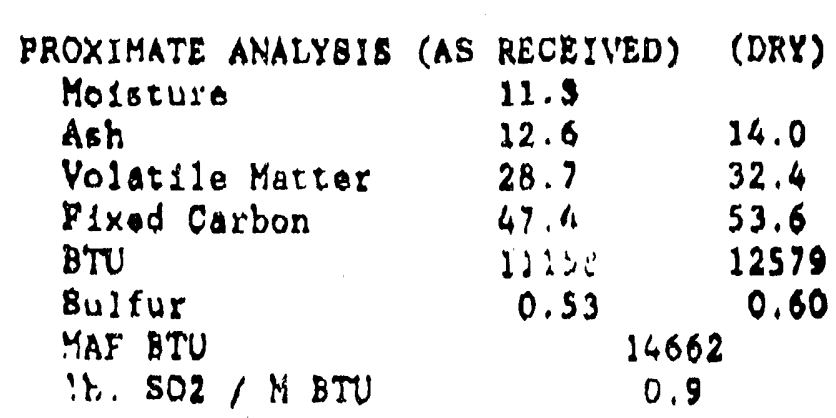

ULTJMATE ANALYSIS (DRY BASIS)

Corbon

Hydrogan

Netragon

Chlorine

Bulfur

Aib

Oxygan

SULFUR FORMS (DRY BASIS)

Pyrdtic Sulfur

Sulfate sulfur

Organdc sulfur

WATRR SOLUBLE ALKALIES (DRY BASI8)

Sodfum Oxido (NE2O)

Potarsium Oxide (K20)

EQUILIBRTUM MOISTURE

FREE SWELLING INDEX

HARDOROVE GRINDABILITY INDEX
ASH FUSION

Roduains Atmouphere

Intelol Dofsirmation Tomp, $8 \quad 2160$

Softening T(imp, $F(H \cup W) \quad 2200$

Hom 1ophardacld Temp, $F(H=1 / 2 W) \quad 2215$

Fiuid Tamp, $F$

Oxidfalne Atmeisphare

Indtial Dofciratelon Temp, $T 2180$

Softening Temp, $8(H$ tW $) \quad 2200$

Healupherich.l Tomp, $F(K=1 / 2 W) \quad 2215$

rludd Tomp, F

2290

ANALYSIS OF AEK (IONITED BABIS)

Phosphorou. Pontoxide (P2OS)

0.2

\$111ca ( 8102$)$

Terrlc Oxldo (Fu203) 8.2

Alumina (A1203) $\quad 14.9$

Titand (T102) 0.7

LImo (CAO) 2\$.1

Magnerio (M8) 1.9

Sulfur Trloxide (803) $\quad 8.0$

Potarsium Oxide (K2O) $\quad 2.24$

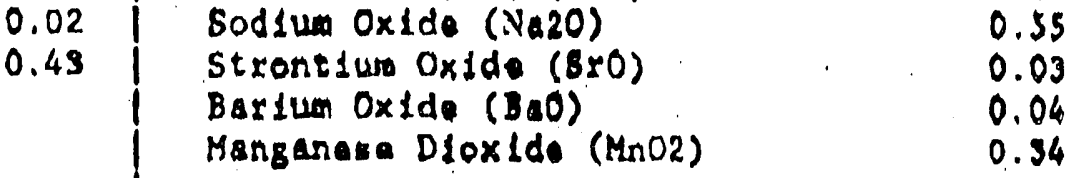

\begin{tabular}{l|ll}
0.02 & Sodiun Oxide (Na2O) & 0.55 \\
$0.43 \mid$ Strontiur Oxide (BrO) & 0.03 \\
Barium Oxide (BaO) & 0.04 \\
Manganasa Dloxldo (MnO2) & 0.34
\end{tabular}

\begin{tabular}{l|ll}
0.02 & Sodlum Oxide (Na2O) & 0.55 \\
$0.43 \mid$ Strontiur Oxide (BrO) & 0.03 \\
Barium Oxide (BaO) & 0.04 \\
Manganase Dioxldo (MnO2) & 0.34
\end{tabular}

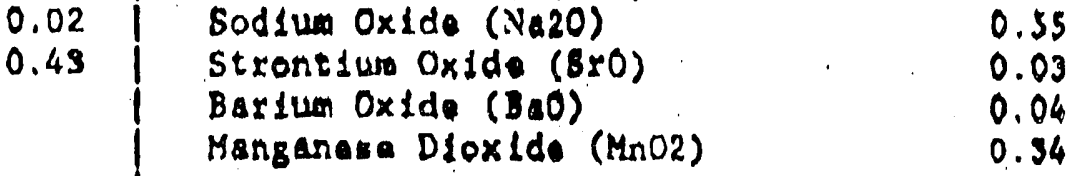

0.020

0.004

ALKALIES AS Na2O

0.27

0.70

BAEE/ACID RATIO

0.70

8.3

B

32.12

SILICA VALUE

3.5

62

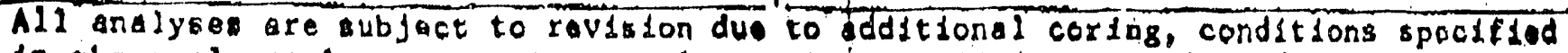
In the coal aupply agreement, actual operating oondition at time of mining, type $\therefore$ proparation of tim of mining, or foderal and tato regulationa. Analyols intended far informational purposas only.

\footnotetext{
8OUTC : PROXIHATE ANALYSIS BASED ON ANALYS I8 OF 123 CORES WITH . S" $^{\prime \prime}$

of : EXTRANEOUS. REMAINDER OF ANALYSIS BASED ON CORE COMPOSITE

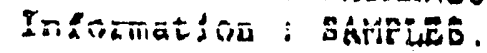

$$
\text { C-6 TOTAL P. } 83
$$




\section{ATTACHMENT D}

PSD Results on Calibration Slurries (SQ3') 


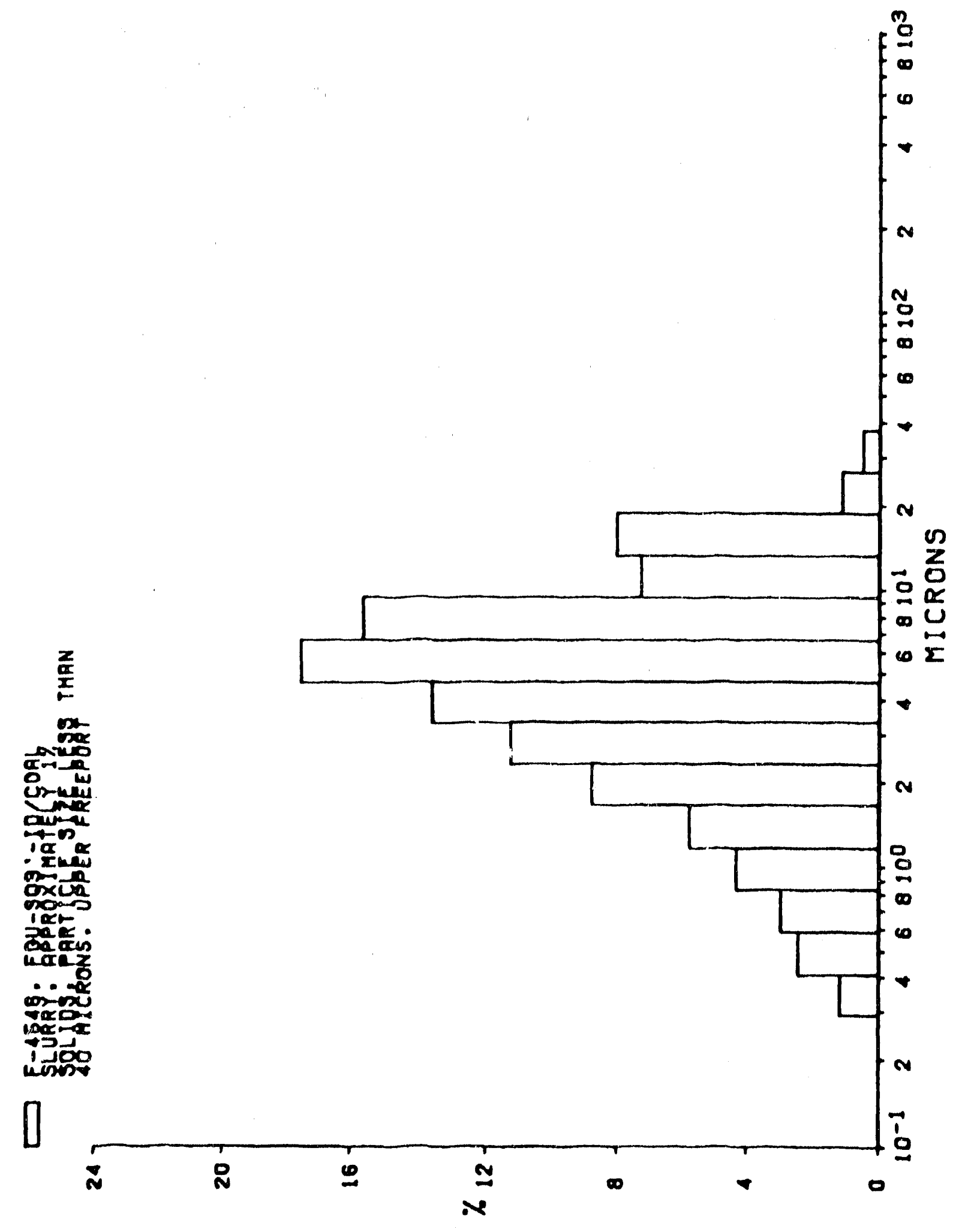

D-2 


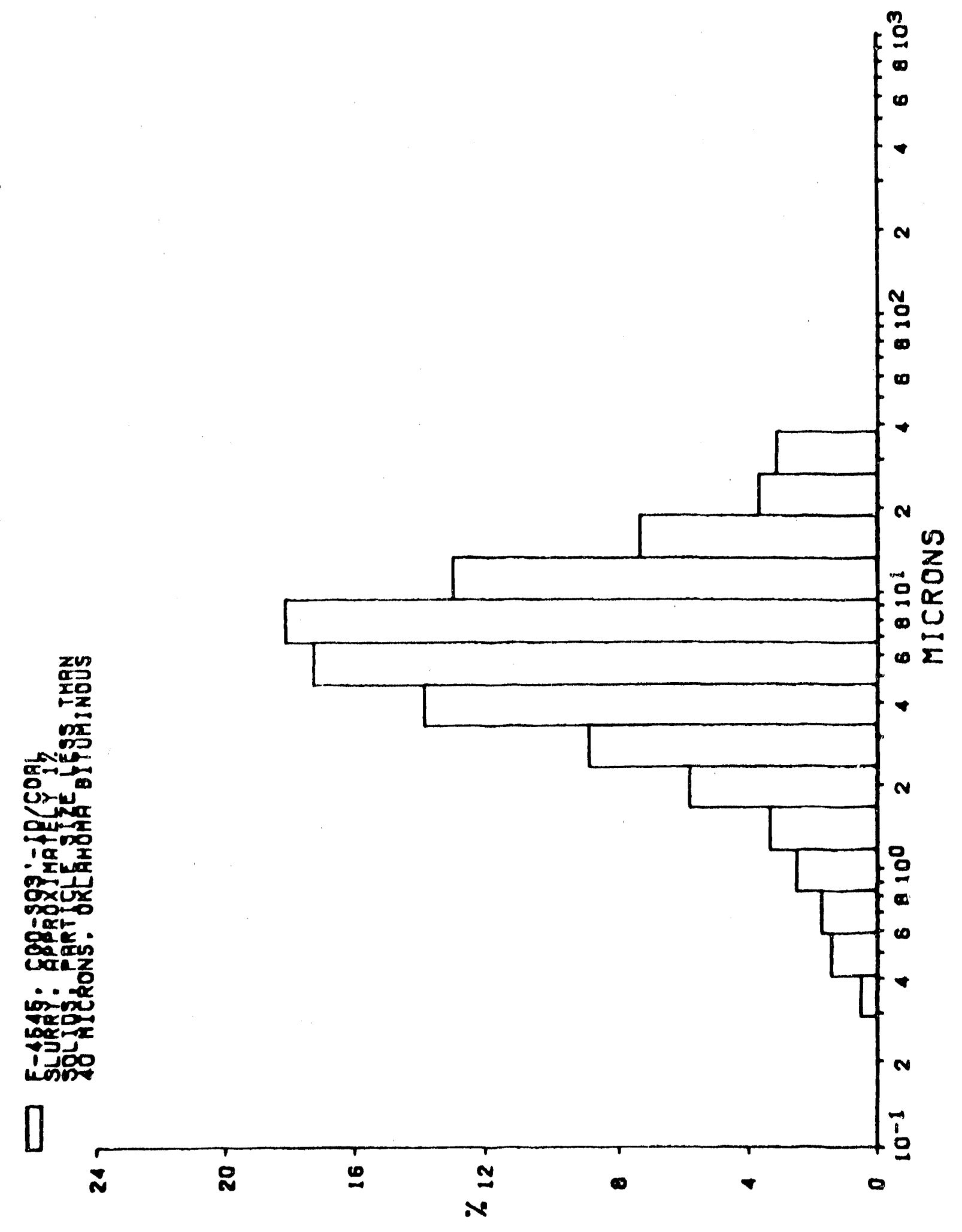

D-3 


\section{ATTACHMENT E \\ Results of opacity Calibration and Solids Testing on Field Collected slurries}




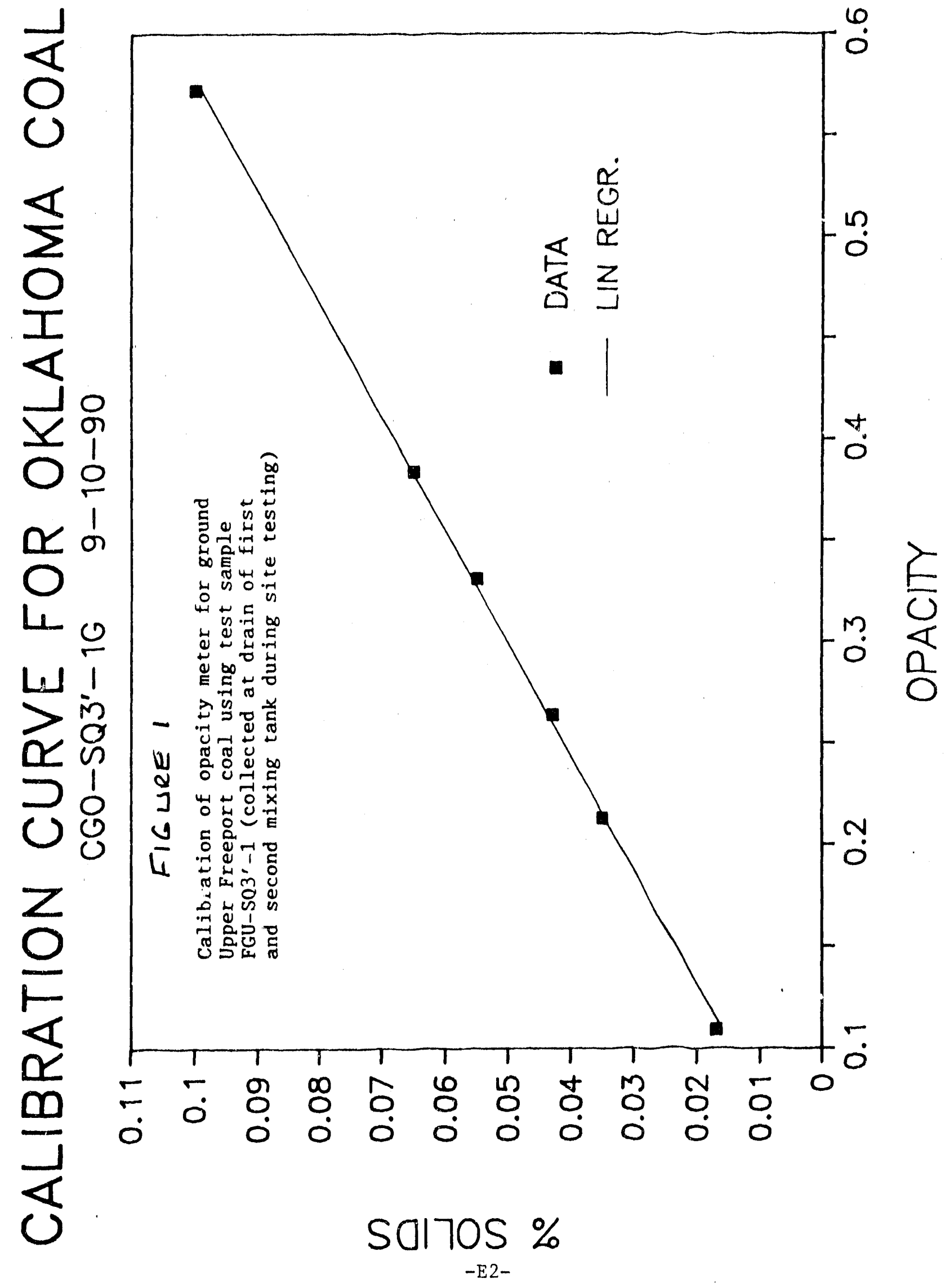




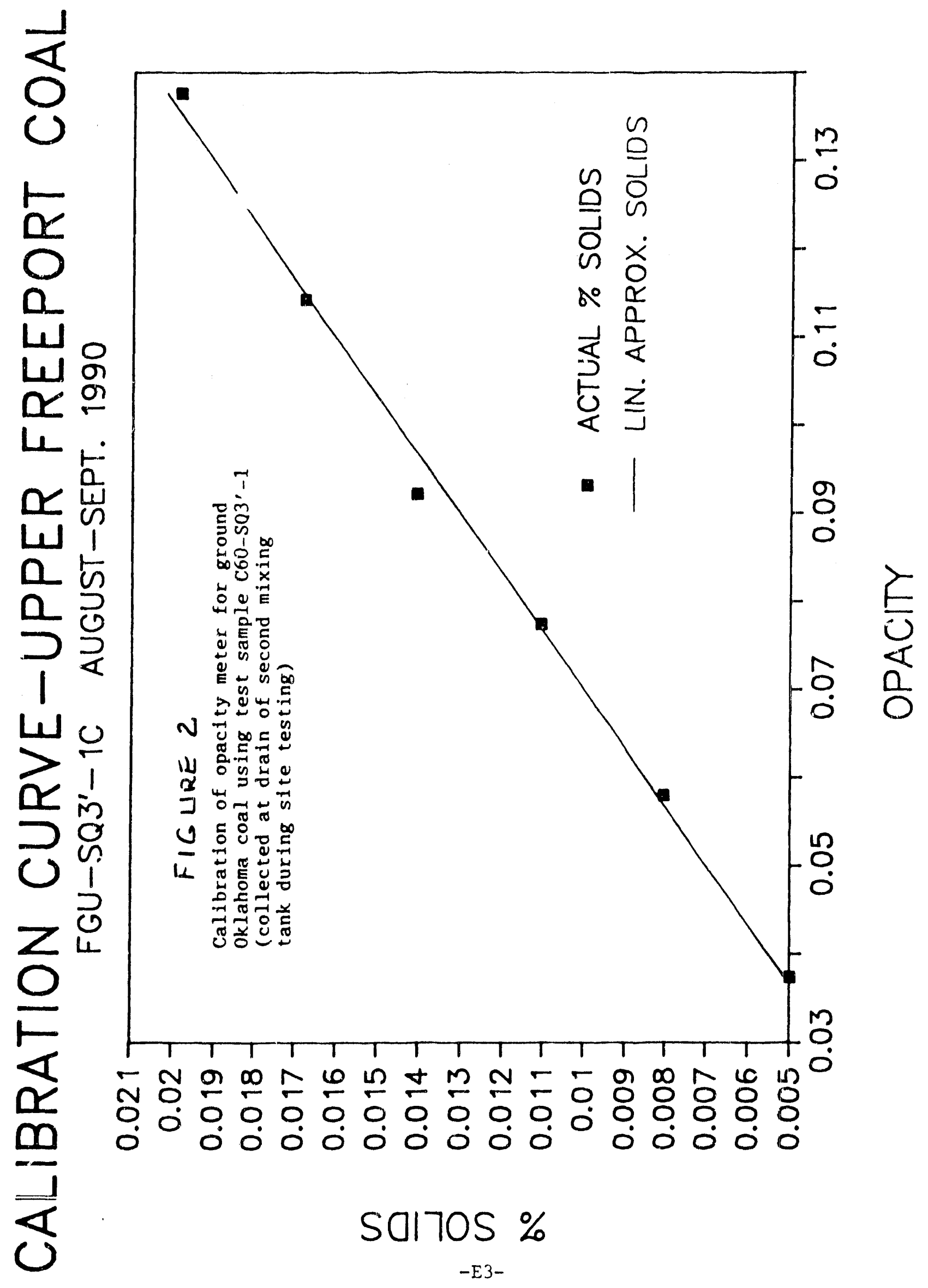




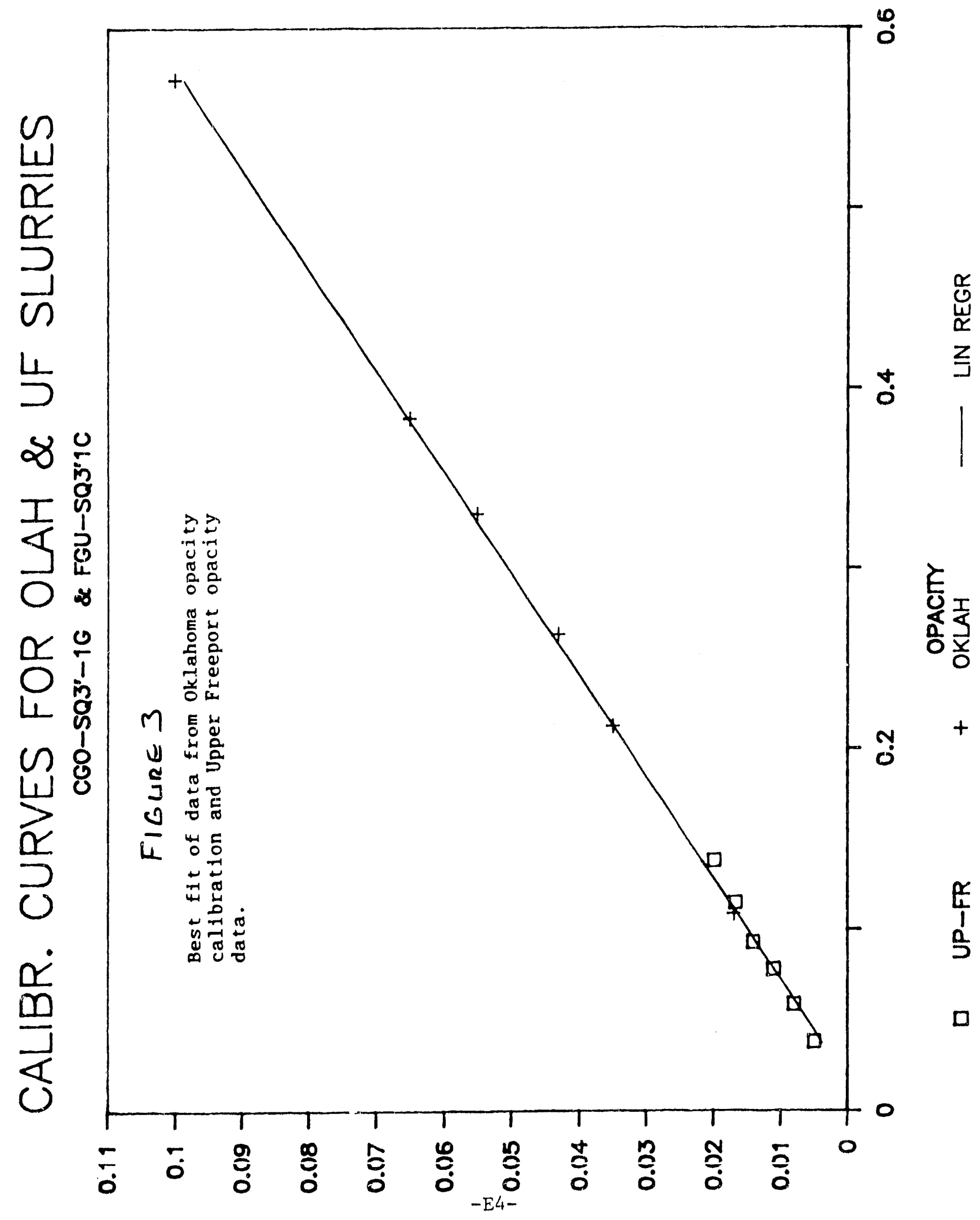

Salnos $x$ 


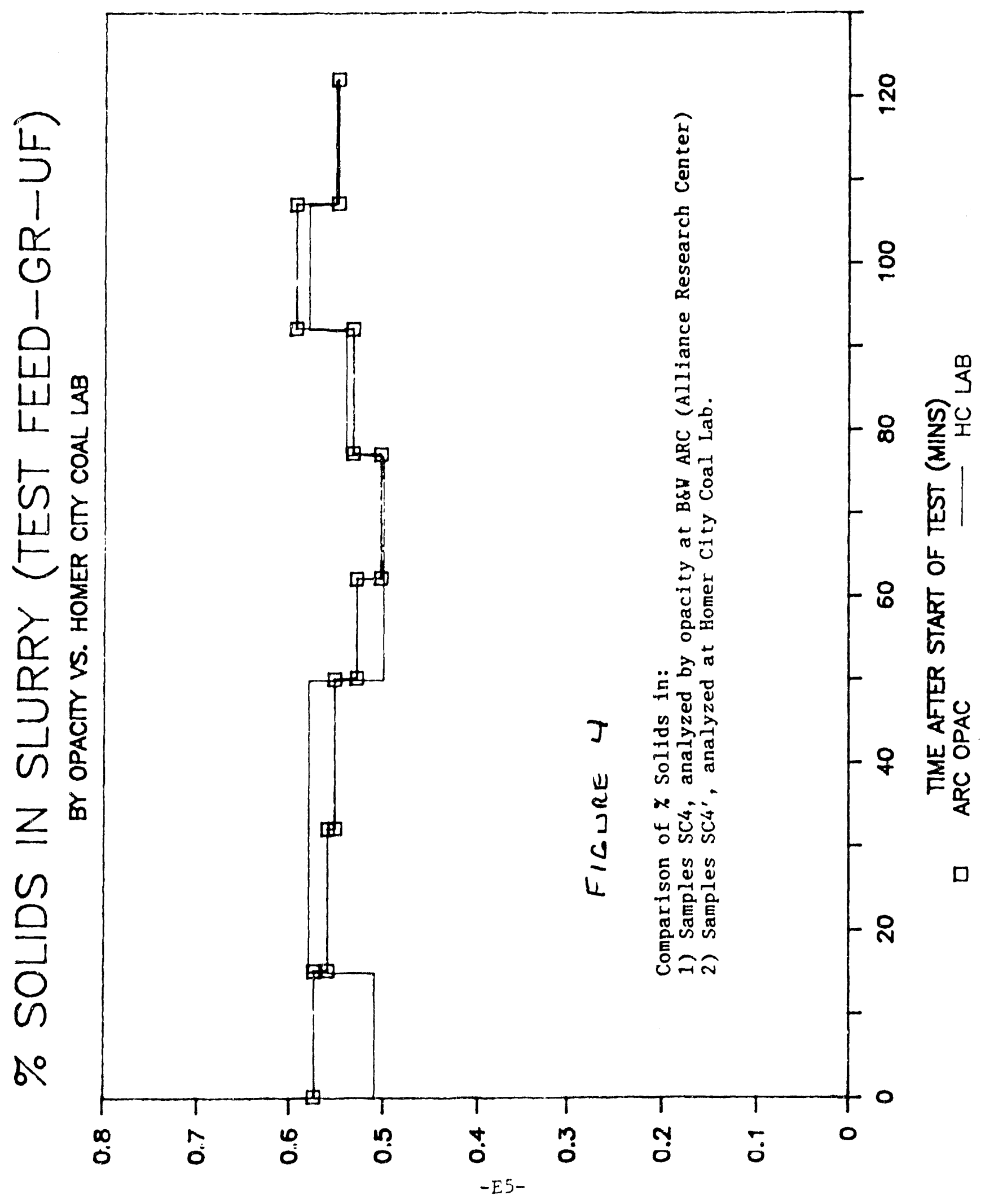

solnos $x$ 


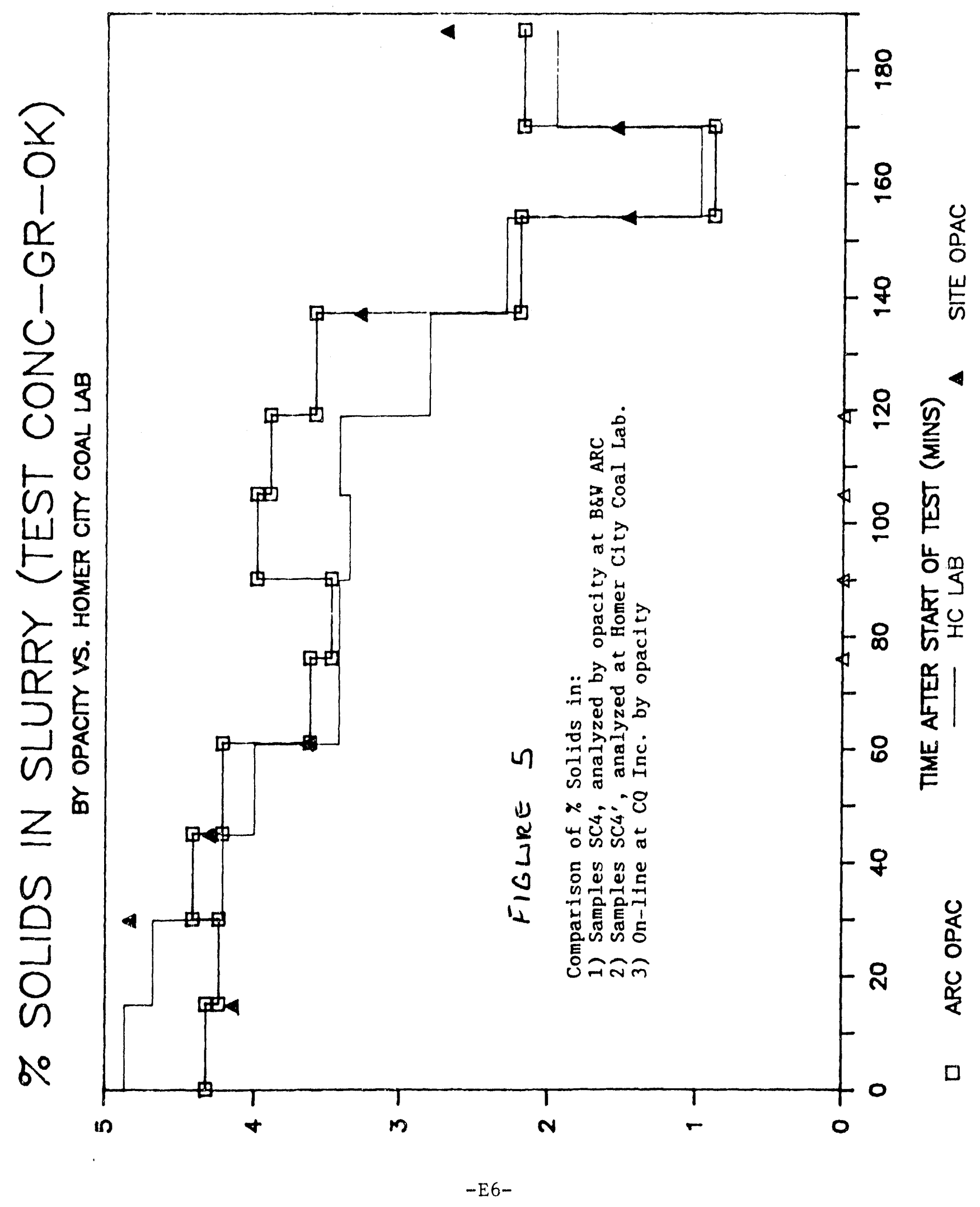



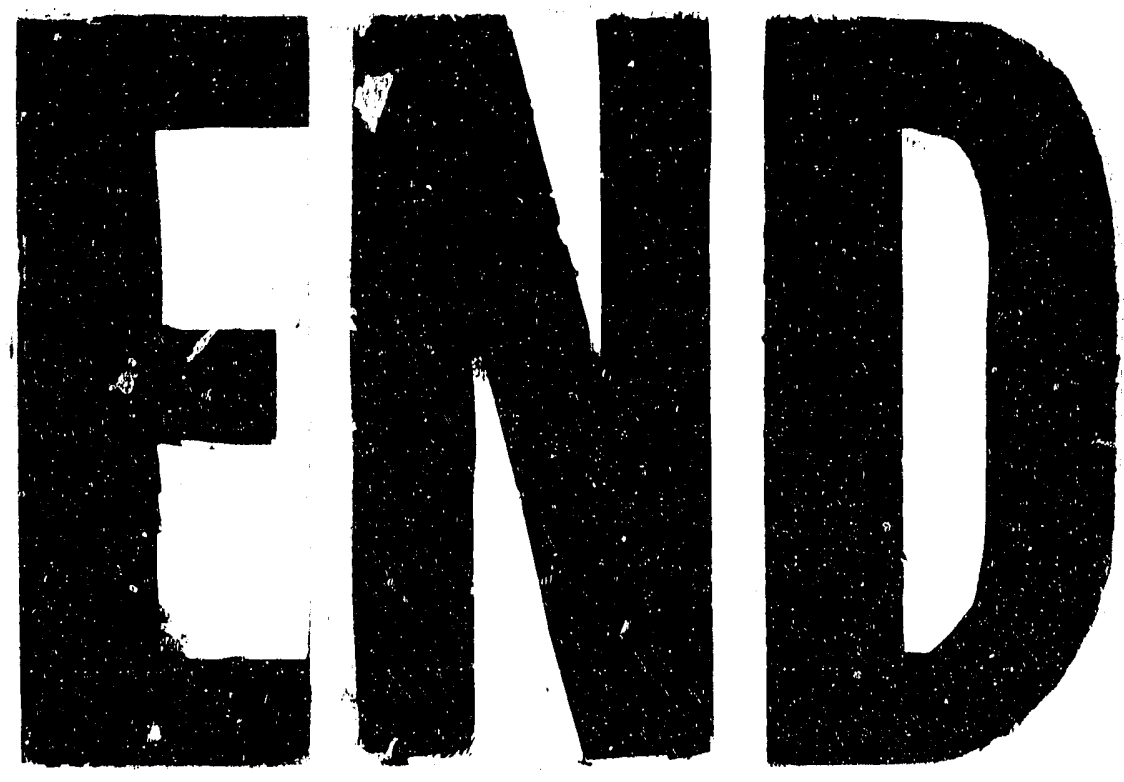

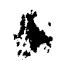
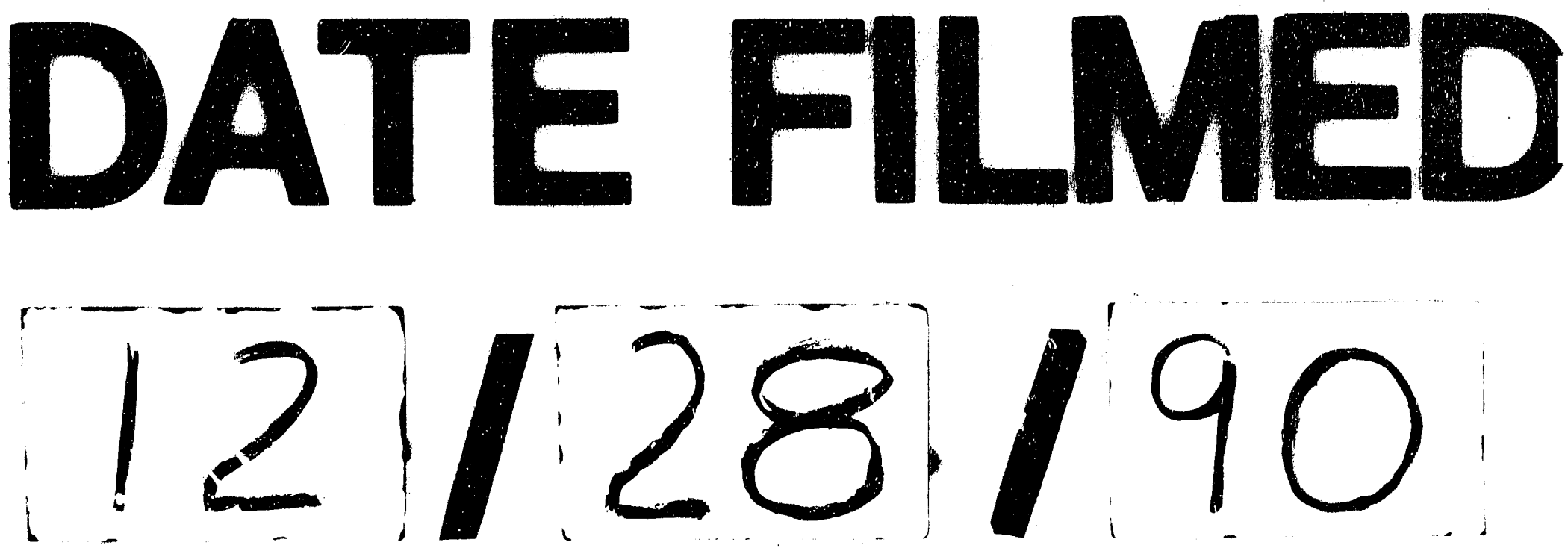
